Global Poverty Research Lab Working Paper Series

\title{
Leader Selection and Service Delivery in Community Groups: Experimental Evidence from Uganda
}

\section{Erika Deserranno}

Global Poverty Research Lab, Northwestern University Kellogg School of Management

Miri Stryjan

Ben Gurion University of the Negev

Munshi Sulaiman

BRAC International

Working paper no. 17-106

October 31, 2017

Keywords: financial services, public services, service delivery, leadership, leaders

\section{Northwestern}

GLOBAL POVERTY

RESEARCH LAB 


\title{
Leader Selection and Service Delivery in Community Groups: Experimental Evidence from Uganda*
}

\author{
Erika Deserranno, Miri Stryjan, Munshi Sulaiman
}

October 31, 2017

\begin{abstract}
In developing countries, NGOs and Governments often rely on local communitybased groups for the delivery of financial and public services. This paper provides causal evidence of how the design of rules used for group leader selection affects leader identity and shapes group service delivery. In collaboration with the NGO BRAC, we randomly assigned newly-formed Savings and Loan Groups to select their leaders using either (i) a procedure in which final outcomes are decided in a public discussion and (ii) a procedure in which final outcomes are decided in a private vote. Leaders selected with a private vote are found to be less positively selected on socioeconomic characteristics than those elected in the public procedure, and at the same time more representative of regular group members. Furthermore, selecting more representative leaders - through a private vote - results in groups that are more inclusive towards poor members by giving them more credit and retaining them longer. Three years after their creation, vote groups are more inclusive than discussion groups, without becoming less economically efficient.
\end{abstract}

\footnotetext{
*Erika Deserranno: Kellogg School of Management, erika.deserranno@kellogg.northwestern.edu. Miri Stryjan: Ben Gurion University of the Negev, miristry@bgu.ac.il. Munshi Sulaiman: BRAC International, munshi.sulaiman@brac.net. We would like to extend our gratitude to the staff of the BRAC Uganda Karamoja initiative, in particular to Albert Ssimbwa, and to the BRAC Uganda Research and Evaluation Unit. We also thank Emanuele Brancati for excellent research assistance. This paper has benefited from helpful comments from Ingvild Almås, Tessa Bold, Jonathan de Quidt, Selim Gulesci, Andreas Madestam, Torsten Persson, Johanna Rickne, Anna Sandberg, Rohini Somanathan, David Strömberg, Jakob Svensson and Anna Tompsett, as well as from seminar participants at the IIES, the OXDEV Workshop, Hebrew University, Ben Gurion University, CERGE-EI, Universidad de los Andes, Warwick, Delhi School of Economics, ISI Delhi, LSE Alumni conference, Chicago PE conference, IEA Mexico and the CSAE conference. This research was supported by grants from Handelsbanken's Research Foundation, the Mannerfelt Foundation, the Nordic Africa Institute and the United States - Israel Binational Science Foundation (BSF). IRB approved.
} 


\section{Introduction}

In many developing countries, access to financial and public services is severely limited, especially among the poorest community members. In this context, NGOs and Governments often rely on local groups (such as farmer associations, microfinance groups, school management committees, community health groups) to deliver these services (Mansuri and Rao 2012). ${ }^{1}$ Delegation of service delivery to local groups has the advantage of lowering program costs as compared to employing external staff, and can facilitate outreach and targeting by leveraging local knowledge. At the same time, however, these groups are embedded in local power structures that can enter their governance and create a bias in favor of influential community members. Understanding whom to select as group "leaders" and how to select them therefore has key implications for service delivery at the local level.

This paper provides causal evidence of how electoral procedures affect the identity of group leaders, and how this in turn shapes the coverage and the targeting of group services. During the creation of 92 new Savings and Loan Groups in rural Uganda, we randomly assigned group members to select their leaders using one of two different participatory and inclusive selection rules: (i) a public discussion or (ii) a private (secret ballot) vote. Our goal is to determine whether the procedure used to select leaders can affect the allocation of services.

The local groups analyzed in this paper were created by the NGO BRAC with the goal of providing access to financial services in a context where such services were previously virtually nonexistent. Each group is formed by up to 30 young local women who deposit savings with the group on a weekly basis; and can take loans out of these savings. ${ }^{2}$ Groups are managed by 5 elected Committee Members (henceforth, CMs) who receive training from BRAC and are then asked to act as leaders. These CMs play an important role: in addition to managing the regular group activities, they decide how to allocate loans across group members. While explicitly instructed by BRAC not to exclude the poorest members, the difficulty of monitoring them gives them the ultimate power of deciding which individuals are given loans. Their decisions thus have obvious implication on whether access to savings and loans is equitable.

Our experiment creates random variation in the procedure used by groups to select

\footnotetext{
${ }^{1}$ Such groups serve millions of households around the world and have been studied in Björkman and Svensson (2010); Grossman (2014); Baland et al. (2015); Burlando and Canidio (2017) among others.

${ }^{2}$ Loans are repaid to the group at a $10 \%$ interest rate. Accumulated interest rates are shared among group members in proportion to the amount of money each person saved.
} 
their CMs. In what we will refer to as the discussion groups, group members are asked to publicly discuss which of them is best suited for the CM positions until reaching an agreement on whom to appoint. In vote groups, members hold a similar public discussion which is, however, followed by a private vote. In this vote, group members are asked to secretly indicate their preferred candidate for each committee position, regardless of whether this person was nominated in the public discussion. The person with most votes is appointed. Apart from the selection procedure, other meeting details are held constant across the two treatments. For instance, the CM selection always takes place in a meeting attended by all group members and where a BRAC staff is present, and the CM positions are always filled sequentially.

The two selection procedures analyzed in this paper are commonly used in direct democracy setups. They differ in the publicness of decision making, a component which can strongly influence the outcome of the decision making process. On the one hand, publicness allows for coordination which may lead to decisions of higher quality (Humphreys et al. 2006). In our context, this would translate into electing more qualified CMs. On the other hand, when decision making is public, less powerful members can be coerced or intimidated into supporting certain proposals, tilting selection decisions towards outcomes that are less representative of low-income group members' preferences (Hinnerich and Pettersson-Lidbom 2014). In contrast, the opportunity to cast a secret vote has been shown to increase the representation of economically disadvantaged groups (Baland and Robinson 2008) and, in our context, this entails more representative CMs. Both the degree of representativeness and the qualifications of the elected CMs are, in turn, likely to affect the nature of service delivery (Pitkin 1967; Osborne and Slivinski 1996; Besley and Coate 1997; Besley et al. 2005).

To estimate how the decision making process affects the CM choice, and to shed light on the tradeoff between CM representativeness and skill, our analysis proceeds in two steps. We begin by comparing characteristics of selected CMs. We then examine group performance by analyzing data on loans, savings and membership that we collected one year (midline) and three years (endline) after committee selection. A key outcome variable is the group's inclusiveness towards the poor, i.e., the proportion of loans that are assigned to poor members and the likelihood that a poor stays in the group.

We find that selection rules affect the type of group leader chosen. Vote groups select CMs who are more representative of the average group participant in terms of economic status than the CMs selected in discussion groups. Individuals belonging to the group's top wealth quartile (as measured with a wealth score used by BRAC in the 
field) are indeed $31 \%$ less likely to be appointed CMs in the vote than in the discussion treatment; those in the bottom quartile are instead 11\% more likely to be appointed. While CMs in vote groups are more representative, they are also found to be potentially less "qualified," as they have less education and less business training. ${ }^{3}$ These findings reveal differences in $\mathrm{CM}$ characteristics between treatments but do not indicate which treatment selects the "best" leaders and optimizes service delivery. We turn to this next.

Vote groups are found to be more inclusive towards poor members than discussion groups: not only do they allow poor members to borrow more money, they are also more likely to retain them. More precisely, in vote groups, poor individuals (belonging to the bottom quartile of their group's wealth score distribution at baseline) are equally likely as richer members to access loans and to remain in the group. In discussion groups, instead, poor members are $28 \%$ less likely to be assigned a loan and $16 \%$ less likely to stay in the group. In line with this, we find suggestive evidence that the treatments also have different effects on wealth distributions over time: the gap in endline wealth score between the initially poorest and the other group members is wider in discussion groups than in vote groups.

The higher inclusiveness observed in vote groups does not come at the expense of efficiency: both treatments have comparable default rates and average loan sizes. If anything, vote groups seem to be more sustainable. Not only do they retain a larger proportion of members, but their probability of collapsing (i.e., retaining none of the original members) in the short-run is also significantly lower, at $2 \%$, than in the discussion treatment, where $15 \%$ of groups had lost all their original members at midline.

Finally, we show that differences in group outcomes across treatments are most likely explained by a leader selection effect (i.e., the fact that decision making rules affect the type of leaders selected). Other mechanisms through which the treatments may affect group outcomes directly - such as a legitimacy effect where members remain longer in the group if they found the leader selection rule more legitimate - are unlikely to explain our results. ${ }^{4}$ All together, the findings of this paper suggest that it is important to limit elite capture at the selection stage, even if at the cost of recruiting a less educated

\footnotetext{
${ }^{3}$ Whether any leader selection process can deliver both highly-qualified leaders and broad representation fundamentally relies on the distribution of qualifications in the population. In our context, qualifications are rare and mostly concentrated within (what we will refer to as) a the wealthy elite.

${ }^{4}$ We discuss why in Section 6.3.
} 
person. We show that introducing a secret vote is a successful way to do so.

The paper bridges two recent strands of literature on community-based service delivery in developing countries. First, we contribute to the literature that studies whether the procedure used to select development projects (rather than leaders) affects the type and location of these projects. Recent evidence suggests that projects emerging from more inclusive procedures, that give voice to a larger fraction of the community (e.g., plebiscites), are more likely to benefit the poor than projects emerging under more centralized decision rules (Olken 2010; Beath et al. 2017; Madajewicz et al. 2017). Second, we relate to recent evaluations of programs that employ local delivery agents as service providers, either within the context of community groups (e.g., microfinance credit officers, leaders of farmer associations) or in non group settings (e.g., community health workers, agriculture extension workers). These studies show that, in an otherwise identical program setting, the type of agents selected makes a significant difference for how benefits of the program are distributed among community members (Bandiera et al. 2017; Deserranno 2017). ${ }^{5}$ We complement these two literatures by showing that, in the context of group-based service delivery, (i) the way leaders are selected strongly influences who is appointed and that (ii) the type of group leaders selected affects the targeting and the coverage of local delivery programs.

Our findings also add to the political economy literature on electoral rules, leader selection and policy outcomes. Due the difficulty to find exogenous variation in electoral rules in real world contexts, this literature has been mostly theoretical (see Huber et al. 1993; Cox 1997; Persson and Tabellini 2002, 2005). We are aware of only one experimental work, Beath et al. 2016, that estimate the effect of at-large voting vs. voting by districts on leader selection in Afghanistan. More closely related to our paper, Grossman (2014) exploits a natural experiment to show that executive directors of farmer associations act in a more accountable way when elected in a direct rather than an indirect election. ${ }^{6}$ Along with the above-mentioned studies on development projects

\footnotetext{
${ }^{5}$ In the context of an extension agriculture program and two heath programs, Ashraf et al. 2016; Deserranno 2017; Bandiera et al. 2017 show that the extent to which the poorest community members are successfully targeted depends on how prosocially motivated the agent is and on the structure of her social preferences. Banerjee et al. (2013); Beaman et al. (2014); BenYishay and Mobarak (2015) find that the aggregate adoption of a beneficial technology is a function the number of connections of the selected delivery agents.

${ }^{6}$ Related work on public vs. private political voting in heterogeneous and polarized populations indicates that public procedures generate outcomes that are less representative for the preferences of low-income community members (Baland and Robinson, 2008; Hinnerich and Pettersson-Lidbom, 2014). We compare public to private decision making in relatively homogenous neighborhood based groups, and whether the same patterns hold in such a setting is an open question.
} 
(Olken 2010; Beath et al. 2017; Madajewicz et al. 2017), Grossman (2014) compares direct to indirect participation rules, and hence focuses on the effect of removing restrictions to participation in decision making fora. In contrast, our paper studies the impact of varying (direct) electoral rules among a comparable set of participants (all the group members). While our findings may not generalize to national elections, they provide new evidence on the design of rules for selecting leaders in community groups which, given the strong presence of such groups in developing countries, complements studies of the effects of national and district elections on service delivery.

Finally, our paper contributes to existing research on how to improve the pro-poor targeting of development programs and their inclusiveness (e.g., Galasso and Ravallion 2005; Bardhan and Mookherjee 2006; Alatas et al. 2012; Niehaus and Atanassova 2013; Burlando and Canidio 2017; Baird et al. 2013). ${ }^{7}$ Rather than focusing on the identification of poverty and eligibility indicators, we take a different approach and examine the impact of group governance on access to services delivered by the group, akin to targeting in our context. To the best of our knowledge, our study provides the first experimental findings on the role of group governance for targeting in community based service delivery.

The rest of the paper is organized as follows. In the next section, we present the geographical and institutional context in which the study took place and describe the experimental setup. In section 3, we lay out the conceptual framework of the study. Section 4 describes the data and presents balance checks. Section 5 presents the treatment effects on committee member selection. Section 6 presents results on group performance, focusing on inclusiveness and sustainability. Section 7 concludes.

\section{Context and Empirical Design}

\subsection{BRAC's Savings and Loan Groups in Karamoja}

This study took place in Karamoja, a region located in North-Eastern Uganda, bordering Kenya and South Sudan. It is the poorest region in Uganda with $74 \%$ of its

\footnotetext{
${ }^{7}$ Baird et al. (2013) study how the definition of sub-national units combined with eligibility indicators can determine to what extent a program is pro poor or becomes susceptible to capture, while (Banerjee et al. (2009) shows that the targeting differs depending on whether a program is implemented by the government or by an NGO. Closer in spirit to our project, Alatas et al. (2012) finds that community-based targeting performs worse in identifying the poor compared to classifying poverty according to a number of pre-determined criteria.
} 
population living below the local poverty line of 1 USD per day compared to $19.7 \%$ in the country as a whole (Uganda Poverty Status Report 2014). The inhabitants of the region traditionally relied on agro-pastoralism and pastoralism for their livelihood, but these livelihood options have become compromised in the last few decades, due to conflict and insecurity combined with harsher climate conditions. Relying solely on agriculture is not a viable option in this semi-arid region and small-scale market activities have gained increased importance in Karamoja in recent years. Access to finance, however, remains extremely low. Microfinance institutions have not established themselves in the region, and savings groups, such as "Village Savings and Loan Associations" (VSLAs) and SACCOs (local credit unions), were also rare at the time of the study.

In this context, our partner institution BRAC - one of the largest NGOs in the world - introduced a credit program in 2011 in collaboration with UNICEF. The program aims at improving access to basic financial services through the formation of local groups that accumulate savings and extend loans to its members. Like all BRAC's activities, the program has the ultimate goal of empowering poor women. As such, the program is open to young women only and aims to "reach the poorest borrowers and savers (...) who remain unserved by other mainstream financial institutions and banks" (Strategic Plan for BRAC Uganda 2011-2015). In exploratory interviews conducted in 2011 before the program was launched, none of the local women (who later joined the program) were saving in a bank or a microfinance institution and only 4 out of 200 interviewees were members of a VSLA or a SACCO before joining BRAC's groups (Czuba 2011, 2012).

BRAC's activity in Karamoja takes place in 114 local centers structured around 9 branch offices, each with a defined catchment area. ${ }^{8}$ During the centers' opening hours its members - who are all young women from 13 years of age and up - can spend time in the center structure and engage in leisure activities such as board games. ${ }^{9}$ In mid 2011, each center member was also invited to join a separate savings and loan group which is our focus in this paper. Each group was composed of up to 30 self-selected members and was organized around weekly meetings where savings were collected and placed in a box. Because savings accumulate slowly over time, loanable funds were

\footnotetext{
${ }^{8}$ Three branches are located in the Napak district, two in the Nakapiripirit district, two in the Moroto district and one in the Kotido and the Amudat districts.

${ }^{9}$ These groups are part of BRAC Uganda's broader program "Empowerment and Livelihood of Adolescents" (ELA) that has been studied by Bandiera et al. (2014).
} 
initially scarce and loans were provided only after the first 6 months of savings.

Group loans have a 4-month cycle and are repaid to the group at a $10 \%$ flat interest rate in 4 monthly installments. ${ }^{10}$ A member is allowed to have only one outstanding loan at a time. Interest rate payments are accumulated in the group for a whole year and, by the end of the year, are shared among group members in proportion to the amount of money each person saved. Members who leave the group in the middle of the year can reclaim their savings but get no share in the group's profits from accumulated interest rates. BRAC encouraged the loans to be used for productive purposes. In practice, around $85 \%$ of the loans were used for business activity while the remaining loans were used to cover school and medical fees and other household related expenses.

In line with BRAC's anti-poverty focus, the loans do not require any collateral and groups do not require a registration or membership fee, nor a minimum amount saved in the group. Moreover, even though poor members typically save smaller amounts than richer members, BRAC explicitly asks group leaders not to exclude marginalized individuals from accessing a loan. These groups are thus formed with the idea of incentivizing the richest members to save in the group, by offering a positive interest rate on savings. ${ }^{11}$ Meanwhile, the poorest members are given the opportunity to save and borrow from the group in a context where formal or semi-formal credit is almost nonexistent. $^{12}$

\footnotetext{
${ }^{10}$ This is in line with the 9\%-10\% interest rate offered by most VSLAs in Uganda on similar loans (Burlando and Canidio 2017) and substantially lower than the $25 \%$ interest rate imposed by most microfinance institutions in rural Uganda.

${ }^{11}$ As noted above, the vast majority of members had no access to alternative formal/semi-formal sources of savings (banks, SACCOs or VSLAs). The means of financial saving available to them are saving money at home or with someone. Aside from not paying any interest rate, such saving forms may also be less secured due to the risk of theft, to pressure from relatives to share the money and to self control problems (e.g., Dupas and Robinson 2013a,b).

${ }^{12}$ The VSLA model is similar to the one of the groups studied here: they typically have a group size of 20-30 people, meet on a weekly basis, do not impose a fixed saving contribution and offer loans with a comparable duration and interest rate (Burlando and Canidio 2017). The key difference is the pro-poor focus: unlike the BRAC groups in our study, VSLAs often impose a registration fee, loan sizes are proportional to the amount saved by the borrower, and loans are often provided to the members who save the most (i.e., the richest). Moreover, VSLAs are typically more "autonomous:" in the sense the bylaws of a given VSLA are chosen by the group itself rather than by a coordinationg organization, as in the case of the BRAC groups. The goal of this paper is not to test whether the BRAC groups function better or worse than other VSLAs, but rather to estimate how leader selection procedures affect group outcomes within the model used by BRAC.
} 


\section{The role of BRAC staff and groups' Committee Members}

In the initial phase of the program, each of the 9 branches in Karamoja was assigned a full-time BRAC staff whose role was to manage and monitor the saving activities of all groups around the branch. In January 2012, before groups started lending to their members, the local BRAC staff instructed each group to select 5 Committee Members (CMs) that would first undergo a training provided by BRAC and thereafter take over group responsibilities. ${ }^{13}$ It is at the stage of selection of these committees that our experiment took place. ${ }^{14}$

In addition to managing the regular group activities, the CMs have the key role of deciding which group members are allowed to take loans, and through this, influence members' incentive to stay in the group. ${ }^{15}$ Although BRAC encourages CMs to include poor and marginalized individuals as much as possible in the group activities (by assigning them loans and retaining them), the groups' increased autonomy and the difficulty to monitor the groups once committees are elected makes these guidelines hard to enforce. The ultimate decision of whom to target is therefore made by the CMs. ${ }^{16}$

Each CM is also assigned extra individual roles: the "chairperson" leads the discussions in every meeting and is the chair of the Committee, the "treasurer" makes sure the box is stored in a safe location (typically either at her home or in BRAC's office) and counts the savings contribution at every meeting in front of the whole group, the "secretary" is responsible for keeping track of all savings and loan transactions and two

\footnotetext{
${ }^{13}$ The training covered basic concepts of financial literacy and was organized by BRAC in their branch office. CMs from all centers within one branch attended the training together. Since both treatments were represented in each branch, this ensures that CMs in both treatments attended identical training sessions. Spillover or contamination effects between treatments from this joint training are unlikely since the main mechanism through which treatment affects the groups played out before the training took place, i.e., by selecting different types of CMs in the meeting itself.

${ }^{14}$ After leader selection, the frequency with which the local BRAC staff visited and monitored the groups declined. The BRAC staff however kept functioning as "mentors" and remained influential in group governance even after the selection. Since we are not able to observe exactly how this interaction affects group performance, we include branch fixed effects in the analysis to account for this unobservable characteristic, common for all groups within a given branch and fixed over time.

${ }^{15}$ Loan applications are made through a simple form that states the date, the name of the applicant and the purpose of the loan. The form is filled by the applicant and handed in to the Committee at the end of any (weekly) group meeting. After accumulating enough savings in the group and receiving enough applications, the Committee meets and discusses to whom to grant a loan. Decisions about loans are typically made once a month.

${ }^{16}$ Even though they face little risk of losing their position in case they do not follow BRAC guidelines, CMs may still want to avoid excluding the poorest members if they care about equity or if they have higher personal benefits from targeting the poor members (e.g., if they are socially connected to the poor).
} 
("key-holders") are in charge of storing the keys of the saving lock box. We will show that in practice, the effects of our treatments on the selection of CMs is very similar across all committee positions, although slightly stronger for "chairpersons," indicating that these extra individual roles were probably perceived as second order. In most of the analysis, we therefore pool all committee positions together.

Although the CMs do not receive any monetary compensation from BRAC, the $\mathrm{CM}$ position is an attractive one: it provides non-financial incentives (reputation in the group) and career incentives (it increases the chances of being later recruited as a permanent staff in the BRAC branch office). ${ }^{17}$ This, coupled with the fact that becoming CM entails potentially large benefits through access to loans while it involves only a small workload, explains why we are not aware of any group member who was selected CM but refused to accept the position.

Finally, the CM position is an open-ended one. As long as a CM attends the group meetings each week and does not "misbehave" (i.e., does not steal the group's money), a CM can stay in her position as long as she wants. ${ }^{18}$ Similarly, group members cannot be pushed out of the group unless they misbehave (i.e, default on a loan, or fail to show up at group meetings). As we will discuss later, the drop out rate in our context is high both for CMs and for regular members but these quitting decisions are typically not "forced" as a consequence of misbehavior. ${ }^{19}$

\section{$2.2 \quad$ Empirical design}

The study was conducted in 92 groups across the 9 branches. ${ }^{20}$ In all groups, the selection procedure of CMs was divided into two steps.

\footnotetext{
${ }^{17}$ Since data on CMs' promotions within BRAC is not available, we cannot prove this point with data. We do however have data on promotions within the BRAC Uganda health program and can show that agents working as volunteer health promoters are more likely later to be recruited to permanent, paid staff positions within BRAC. This is not surprising: frequent interactions between these local agents and their BRAC supervisors/mentors increases the probability that they learn about vacant BRAC positions and that they are nominated by their supervisors for these vacant positions.

${ }^{18}$ BRACs program initially stipulated a one year term limit but interviwes with local BRAC staff reveal that these were not enforced in practice.

${ }^{19}$ Each time a CM leaves her position, she is replaced by someone else in the group. Since the groups were more autonomous from BRAC at this point, the re-election procedure was not monitored and, in practice, groups could have followed a different procedure than the one randomly assigned when electing the first CMs. This can explain why some of the differences in outcomes between treatments that we observe at midline are attenuated over time.

${ }^{20}$ Before randomization, 22 out of the 114 initially formed groups were excluded from the experiment. Those were considered by BRAC as either too small or too large in size to be "sustainable."
} 
(1) A staff member from the corresponding branch office informed all members that the group was to select a committee in a meeting to be held the following week. Information was given about the role of the committee and about each committee position. The procedure to be used for selection was not revealed at this point, ensuring that if any campaigning took place in the week preceding committee selection, it was orthogonal to the selection rule assigned to a given group. It also ensures that the attendance rate on the day of the meeting is orthogonal to the treatment.

(2) Upon arrival at the meeting, group members were instructed on the procedure they would use to select CMs. Half (46) of the groups were randomly assigned to select CMs using the Public Discussion Treatment while the remaining 46 groups were randomly assigned to the Private Vote Treatment. The randomization was stratified at the branch level. In all groups, positions were filled sequentially: for each committee position in turn, groups were first asked to publicly discuss which candidates were suited for the position and willing to fill it. They then proceeded to the selection stage, which varied by treatment as follows:

Discussion Treatment (Public Discussion): Any group member could nominate a candidate for the position. Other members could then second or oppose the nomination publicly until the group agreed on a name.

Vote Treatment (Private Vote): Each group member was asked to privately vote for their preferred candidate by writing the name on a piece of paper and then placing it in a basket. The local BRAC staff then compiled the votes and the person with most votes was elected. ${ }^{21}$ Importantly, each person was allowed to vote for any of the group members, irrespective of whether the person was mentioned or not during the discussion that preceded the secret vote. This discussion can hence be considered a standard pre-election non-binding discussion with a purely informative goal.

These two selection rules were chosen by BRAC among a set of other potential rules because: (a) they are versions of the globally most common direct participation procedures, (b) they hold relevance also in the Karamoja context, where discussion is used in local village meetings while secret ballot vote is used in national elections and (c) they are enforceable in small groups. The lack of consensus about which of the two rules is more legitimate makes the comparison between them relevant. ${ }^{22}$

\footnotetext{
${ }^{21}$ BRAC staff assisted illiterate members with writing. In the rare case of a tie, the winner was determined by a show of hands. We do not have records of the groups in which this occurred.

${ }^{22}$ In section 6.3 , we show that in our setting both procedures are perceived as equally legitimate ex-ante.
} 
While members were familiar with both public discussion and secret ballot vote, prior to the experiment, the members had little or no experience of being active participants in either one of the two decision making procedures. This is because young women are typically excluded from decision making fora in Karamoja, and the legal voting age in Uganda is 18, implying that the majority of group members has voted in, at most, one national election.

The two treatments differ from each other along two main dimensions. The first one is the degree of publicness of the decision: all support for a candidate is expressed publicly in the discussion treatment while votes are cast privately in the vote treatment. As we discuss further in the next section, this can affect the voting choice of each member as well as the composition of members who actively participate in the leader selection. The second dimension along which the treatments vary is the proportion of votes that a person needs to receive in order to be elected. In the vote treatment, all group members express their choice through casting a vote and the person with most votes is elected (plurality rule). In the discussion treatment, instead, a leader is elected if a consensus is reached, even if only a subset of people decide to actively participate in the discussion. While this simultaneity makes it difficult to disentangle these two mechanisms, we believe that it makes our setup similar to what often occurs in village meetings and other direct democracy contexts. ${ }^{23}$

\section{Conceptual Framework}

In this section, we discuss the mechanisms through which our selection rules-public discussion vs. private vote - can affect committee member (CM) characteristics and how these characteristics, in turn, may affect service delivery and targeting. The literature on political selection has informed our framework, highlighting differences between public and private decision making and a trade-off between representativeness and skills of leaders.

\footnotetext{
${ }^{23}$ One possible way of disentangling these two mechanisms would have been to add a third treatment where a public vote (e.g. a show of hands) determines the final decision. There are two main reasons for why no such treatment was added. Firstly, since public vote is not a method commonly used when making decisions in direct democracy setups, it is less relevant for policy. Secondly, due to the divided nature of society in the Karamoja context, imposing on every member to publicly take sides was deemed problematic by BRAC. For more background on local political decision making in Karamoja, see Czuba (2011, 2012).
} 


\subsection{The effect of selection rules on CM characteristics}

As explained above, the key difference between our two election rules is the introduction of a secret vote in one but not in the other. Theoretically, the introduction of a secret vote has both advantages and disadvantages. On the one hand, it may reduce elite capture and intimidation, leading to more representative CMs. On the other hand, it may reduce coordination, leading to less qualified CMs. Each of these mechanisms are discussed in detail below.

\section{Elite capture and the selection of less representative CMs}

Recent work comparing public and private decision making procedures predicts public discussion setups to result in policy outcomes that represent the interest of more powerful community members, through elite capture and intimidation (Hinnerich and Pettersson-Lidbom 2014), while the introduction of a secret ballot allows disadvantaged citizens to vote more in line with their true preferences and thus generates election outcomes that are more representative of the preferences of the electorate (Baland and Robinson 2008).

If this mechanism is at work, we would expect the vote treatment to produce CMs who are more representative (i.e., more similar in characteristics and preferences to the average group member) than CMs emerging in a public discussion. Decision making under the vote treatment is indeed private: all members express their opinion through a secret vote and everyone has an equal weight in the decision process. The discussion treatment, instead, does not require each and every member to speak up and may thus give more weight to the subset of more powerful members who take an active part in the discussion. ${ }^{24}$ Guided by the pro-poor nature of the BRAC program, we define representativeness in terms of observed socioeconomic characteristics such as wealth, education and tribe (more details on this in Section 4.2). ${ }^{25}$

\footnotetext{
${ }^{24}$ Elite capture can theoretically happen in two ways. First, powerful members may influence the election outcomes by exerting their de facto power and intimidating other group members in the discussion. Second, in contexts in which participation is not compulsory, elite capture may change the composition of participants in the meeting, with less powerful members being less likely to show up. In our settings, all group members participate in the meeting and the second mechanism is hence not at play. In other settings, in which participation is not compulsory, the publicness of decision making is found to reduce the number of agents who show up at meetings (Olken 2010; Madajewicz et al. 2017) with the elite being over-represented.

${ }^{25}$ In a community setting such as the one we study, social connections are also likely to matter. Bandiera et al. (2017) finds that members in the personal network of local delivery agents benefited more from an agriculture extension program, while Grossman (2014) shows that personal ties substitute
} 


\section{Coordination and the selection of more qualified CMs}

The introduction of a secret vote may reduce coordination across the different members and lead to lower quality decisions (Humphreys et al. 2006). This can be the result of the private format being less conducive to an informative discussion about the advantages and disadvantages of the different possible outcomes. Alternatively, this can also happen if, in the private format, members are inclined to vote for candidates they are personally connected to while in the public format they face pressure to support the more qualified person.

If this mechanism is at work, the privateness of the vote treatment would lead to the selection of less qualified CMs. Since the objective of the groups studied here is to encourage savings and give loans for market activities, relevant qualifications for $\mathrm{CM}$ are accounting skills and experience in handling financial transactions, and the ability to keep track of saving and loans. In what follows, we will focus on education, economic performance at baseline, market experience and labor market connections as qualification measures.

In contexts in which leader "qualification" is negatively correlated with leader representativeness, the coordination and the elite capture mechanism have the same prediction: the secret vote procedure should lead to more representative but less qualified CMs. This is the in our context (as in many developing countries): education is rare and the most qualified CMs tend to be richer and therefore less representative. Since the theoretical predictions on observable CM characteristics are the same for the elite capture and the coordination story, we will not be able to perfectly separate them in the data. We will however be able to test whether it is indeed true that the secret vote leads to different types of CMs and will then use this variation to analyze how CMs' types shape group outcomes, as discussed next.

\subsection{The effect of CM characteristics on group outcomes}

Is it optimal for group members to elect a qualified leader if this comes at the expense of representativeness? To answer this question, this section outlines the way in which qualification and representativeness of group leaders are likely to play out in our context.

for rule enforcement in Ugandan farmer group councils. In a similar way, friendship or kinship ties with leaders can proxy for trust and convey information about commonly held preferences (Alesina and La Ferrara 2002). For this reason, we include in our analysis variables such as tribe and the number of group members who are close friends. 
We think of CM qualification as a valence issue, a quality that makes everyone in the group better off regardless of their similarity to the CMs (Besley 2005). A more qualified $\mathrm{CM}$ is able to retain more members, accumulate more savings, allocate more loans and keep the group "active" for a longer period of time.

Representativeness of a CM affects different sub-groups of members in different ways, depending on their similarity to the CMs. This can happen either through favoritism, for example by CMs disproportionally approving loans to members of their own group, or being more lenient with the repayment from such members, or by committees deciding on policy that caters more to the preferences of the CMs own group (Pitkin 1967; Osborne and Slivinski 1996; Besley and Coate 1997; Besley et al. 2005).

Empirically, we estimate the effect of CM characteristics on group outcomes by comparing post-election group outcomes across treatments. The implicit assumption underlying this approach is that the discussion and vote treatments affect group outcomes only through the selection of a different type of CM. As we will discuss in Section 6.3 , alternative channels (such as direct treatment effect on members' satisfaction) are likely less relevant in our setting.

\section{Data and Descriptives}

\subsection{Data and Timeline}

The study was carried out between May 2011 and June 2015 and involves four waves of data (see Figure 1 for a representation of the timeline).

(1) Three months after the groups were formed, between September 2011 and February 2012, a baseline survey was administered to all 1,483 group members. At the time of the baseline, members had already started saving but had not elected CMs.

(2) In February/March 2012, after the baseline was completed, the groups were randomly assigned to either the vote or the discussion treatment, and the CMs were elected in group meetings according to the assigned rule. ${ }^{26}$ From each meeting, we recorded the list of group members who were elected CMs and use this data, along with the baseline data, to compare differences in predetermined characteristics between the CMs selected in the vote vs. the discussion treatment. ${ }^{27}$

\footnotetext{
${ }^{26}$ The committee size deviated from 5 in four cases: one group had 4 CMs, 2 groups had 6 CMs and one group had $7 \mathrm{CMs}$. These differences are not significantly correlated with group treatment status.

${ }^{27}$ Unfortunately, we do not have detailed accounts (minutes) from each meetings.
} 
(3) We estimate the impact of our treatments at two points in time: at midline in March 2013 and at endline in March 2015 (one and three years after the committee selection). At midline, we have BRAC administrative data on (i) whether each baseline member is still part of the group, (ii) the number of loans each member has received from the group in the past year and (iii) the total loan amount she borrowed. This data is available from ledger books in which each BRAC staff was asked to record, each time she visited a group, individual-level financial transactions from each group member.

(4) At endline, we have BRAC administrative data on retention (whether a member is still part of the group) but we do not have the equivalent individual level information on loans. ${ }^{28}$ To fill this gap, an endline survey was administered between April to June 2015. The high dropout rate and the difficulty to track members who had left the groups, made it difficult to survey all baseline members at endline. We hence decided to survey all 345 stayers (baseline members who were still part of the group at endline and who were easy to locate) and a random pre-selected $40 \%$ of the 1,105 leavers. To account for the oversampling of stayers, we use sample probability weights in all endline regressions (Table A1 explains how these weights are calculated).

The endline survey provides us with individual-level transactions within the group: loans received from the group, default rate and cumulating savings. Collecting this information was facilitated by the fact that each member kept passbooks at home in which they recorded their deposits into the groups' saving box and their outstanding loans. ${ }^{29}$ The endline survey also collected self-reported information on financial transactions and savings outside the groups.

\subsection{Summary Statistics and Balance Checks}

Table 1 reports mean and standard deviations for a number of key variables at baseline, separately for the vote and discussion treatment. Reassuringly, these characteristics do not differ significantly across treatments, indicating that the randomization yields a sample that is balanced.

The community groups in our study have an average size of 16 members who are

\footnotetext{
${ }^{28} \mathrm{BRAC}$ staff stopped recording this information at the individual-level soon after the midline. The data was, however, recorded by the committees and efforts were made to recover this data from ledgers that were kept at the local centers. Unfortunately the quality of the data was low, with pages missing or parts of the ledgers having been damaged.

${ }^{29}$ In the rare cases in which the passbook was not available, answers were self-reported and possibly under or over-reported. We will always present midline results (non-self reported) and endline results in the same table.
} 
22 years old on average. $59 \%$ of them are married, $61 \%$ have children and $21 \%$ are still in school. Among the members who are active in the labor market, about half are involved in a non agriculture business. Our baseline survey was conducted after groups had opened, and consequently most members $(83 \%)$ reported to have savings at baseline, mainly in the group. The average amount saved was 17 thousand Ugandan Shillings (UGX). ${ }^{30}$ Only $12 \%$ of the group members had an outstanding loan at baseline and none of these loans are from a bank, a microfinance institution or a VSLA. This further confirms that prior to the launch of BRAC's program, there was a lack of access to financial services in the studied context.

Group member's wealth is measured using an index compiled by the Grameen Foundation and BRAC to identify poor participants in the field. This index combines information on 10 verifiable poverty indicators that are easy to measure, and compiles them into a score from 0 to 100 that has been shown to highly correlate with poverty status as measured by more exhaustive surveys in Uganda (Schreiner 2011). ${ }^{31}$ In our sample, the average wealth score is 26 and the median is 21 . This is 10 percentage points below the median score in Uganda (Sulaiman 2014). Following BRAC targeting guidelines, we define a respondent as being "poor" if she belongs to the bottom quartile of her group's wealth score distribution. Finally, we also proxy wealth with the total value of household, agriculture and business asset holdings. These are based on respondents' self reported ownership and estimated values of these assets.

To proxy for each member's level of qualification related to the CM task we use three different variables: (a) completion of primary school (indicating literacy and basic numeracy), (b) business skills (as proxied by whether she has ever attended a business training) and (c) access to business advice. Schooling rates are low in Karamoja and only half of the members of our sample have ever attended school while only $23 \%$ have completed primary school. $25 \%$ of the members have attended practical business trainings organized either by BRAC as part the center's program, by another NGO or by the government. These trainings aim to improve skills in managing and starting

\footnotetext{
${ }^{30}$ Using the 2011 World Bank PPP-adjusted exchange rate for Uganda (833 UGX/USD), 18k UGX corresponds to 21.61 USD. Using the nominal exchange rate of November 1, 2011 (2,570 UGX/USD), 18k UGX corresponds to 6.83 USD.

${ }^{31}$ These include material of roof, walls and floor of a household's main house, ownership of shoes and clothes for all household members, access to water, sanitation and power sources. Since these are observable measures they are also known by other members in the same community, and it is thus reasonable to assume that members of a given savings group can guess other members' relative poverty level according to this score. See Schreiner 2011 for a more detailed description of the 10 indicators and the weight of each indicator in compiling the total score.
} 
small-scale income generating activities. $29 \%$ of the members report having received advice on earning activities from someone outside of their household in the past year.

Finally, we collected information on other traits that are believed to be positively correlated with the likelihood that a member belongs to a richer and more educated "elite:" whether a member has worked or studied outside her current district (e.g., in the capital) for at least one year, and whether a member belongs to the group's minority tribe. ${ }^{32}$ As shown in Table A.2, there is a positive and significant correlation between education, wealth, belonging to a minority tribe (not belonging to main tribe) and having studied or worked outside the village. This in line with the trade-off identified above: less-representative members - who are richer and belong to the minority tribe - are more educated. For each person, we also report a normalized degree centrality measure: the percentage of other members in the group who reports this specific person as being among the two best friends in the group at baseline. The more popular a person is in the group, the higher this measure.

\section{Treatment Effects on the Selection of Committee Members}

This section studies how different participatory decision making methods - i.e., public discussion versus private vote - affect the characteristics of selected CMs. To test this, we begin by comparing characteristics of the CMs selected in the public discussion treatment to those selected in the private vote treatment by estimating:

$$
Y_{i g b}=\alpha+\beta \text { Vote }_{g}+\theta_{b}+\varepsilon_{i g b}
$$

where $Y_{i g b}$ is an economic or a social characteristic (wealth, education, tribe, etc.), measured at baseline, of CM $i$ elected in group $g$ of branch $b$. Vote $e_{g}$ equals one if the group $g$ is assigned to the vote treatment and $\theta_{b}$ are branch fixed effects. Throughout the analysis, standard errors are clustered at the group level (level of randomization) and the base category is the discussion treatment.

Table 2 reports comparisons between CMs in the vote vs. discussion treatment. It

\footnotetext{
${ }^{32}$ The Karamojong people are divided into five main tribes/ethnic groups: the Bokora in the west, the Pian in the east, the Matheniko in the south and the Dodoth and Jie in the North. In addition, one location in our sample (Amudat) is dominated by the Pokot tribe, a non Karamojong tribe. In the locations we analyze, the Bokora tribe is the most represented tribe on average but also the "poorest."
} 
shows that CMs elected in the vote treatment are significantly poorer: their wealth score is $18 \%$ lower and their assets are worth $40 \%$ less. They are also $4 \%$ less likely to have completed primary school, $33 \%$ less likely ever to have received business training and $40 \%$ less likely to have access to business advice through their networks. They also score lower on socioeconomic proxies than their counterpart in the discussion treatment: fewer of them have worked or studied outside the village and more of them belong to the majority tribe (although this difference is not statistically significant). Altogether, these results support our earlier prediction: CMs elected in the vote treatment are poorer, less educated and have fewer market connections on average than CMs selected in the public discussion treatment. This is in line with them being less likely to be part of the local "wealthy elite."

Table A.3 replicates the above analysis for each of the five CM positions separately. We do not find any stark differences in the "type" of leaders selected across different committee positions, although the results are slightly stronger for the chairperson position. This is the first position that members discussed/voted on, and the one with the highest decision making power. Taken together, the results indicate that the "side" roles of each committee position do not seem to differentially affect type of leader elected across treatments. In what follows, we therefore pool all positions together.

While comparisons between CMs across treatments are useful for identifying selection effects, an even more informative approach consists in studying how elected members differ from non-elected ones, and whether these differences vary across treatments. Individual baseline data on the characteristics of all members (elected and non-elected) allow us to test this:

$$
\text { Committee }_{i g b}=\alpha+\beta Y_{i}+\gamma \text { Vote }_{g}+\delta Y_{i} * \text { Vote }_{g}+\theta_{b}+\varepsilon_{i g b},
$$

where Committee $_{i g b}$ equals one if member $i$ in group $g$ and branch $b$ is elected CM and $Y_{i}$ is an economic or a social characteristic of member $i$ (wealth, education etc.). The coefficients of interest, $\beta$ and $(\beta+\delta)$, estimate whether characteristic $Y_{i}$ is a determinant of being elected in the discussion and the vote treatment, respectively. $\delta$ is the differential predictive power of $Y_{i}$ across treatments.

Panel A of Table 3 shows the results for outcome variables related to member wealth score and assets. In the discussion treatment, members who belong to the group's top wealth quartile are 13.8 percentage points (66\%) more likely to be selected, while they are not more likely to be elected in the vote treatment (Column 5). The results 
for assets point in the same direction (Columns 6-10). The graphical counterpart, presented in Figure 2, plots the position of a member in the group's wealth score distribution, separately for CMs and the other regular members, by treatment. In discussion groups, the distribution for CMs shifts to the right of the distribution of other members, indicating that $\mathrm{CMs}$ are positively selected on wealth. A KolmogorovSmirnov test rejects equality of these distributions at the $99 \%$ confidence level. In the vote groups, instead, the two distributions follow each other, showing no clear selection on wealth, and the difference between distributions is not statistically different.

While both treatments favor members that have completed primary school, the disparity in education level between elected and non-elected members is significantly larger in the discussion treatment than in the vote one (Table 3, Panel B). More precisely, in the discussion treatment, members who have completed primary school are 23 percentage points more likely (twice as likely) to be appointed than the other members. This effect shrinks to almost half in the vote treatment where educated members have only 12 percentage points higher likelihood of being appointed CMs. Similarly, discussion groups select CMs who are more likely to have a business network than the average group member, and who are less likely to belong to the majority tribe. Finally, holding every other member characteristic constant (i.e., adding all characteristics on the right hand side of one single regression), Table A.4 shows that formal education and business training are the key predictors of committee appointment in the discussion treatment, while they do not predict appointment in the vote groups.

To conclude, the results indicate that CMs are positively selected in terms of wealth, education and market connections in the discussion groups while in vote groups they are more representative. As described in the conceptual framework, this is consistent with two possible stories.

(1) The vote treatment reduces elite capture or intimidation and gives more weight to the less powerful members of the group - i.e., the poorest members - to influence the political outcome of the vote. This generates leaders who are less likely to belong to the wealthy elite and instead are more representative of the group as a whole. In a context where education and training are rare and positively correlated with wealth, less wealthy leaders are also less educated and less trained.

(2) The secret vote allows for less coordination than the public discussion and therefore enables the selection of CMs that appear less qualified for the task (proxied by lower education and training).

Although we are not able to completely disentangle these two stories, our treatments 
create variation in the type of group leaders selected. In the next section, we use this variation to shed light on the very important but understudied question of whether it is better to elect more educated but less representative group leaders or vice-versa.

\section{Treatment Effects on the Inclusiveness and Sus- tainability of Community Groups}

This section studies which electoral rule leads to more inclusive and sustainable groups, where inclusiveness is defined as the likelihood that a poor member is assigned a loan and retained in the group, while sustainability refers to the likelihood that the group remains operational.

In Sections 6.1 and 6.2 we estimate individual and group-level treatment effects. In Section 6.3, we show evidence supporting our claim that differences in outcomes across treatments are likely explained by differences in leader "types" (i.e., more representative but less educated CMs in vote groups), rather than by other mechanisms through which the selection rules could have affected group outcomes independently of leader types.

\subsection{Member-Level Results}

To study the treatment effects on loan delivery we estimate:

$$
Y_{i g b}=\alpha_{1}+\beta_{1} \text { Vote }_{g}+\theta_{b}+\varepsilon_{i g b}
$$

where $Y_{i g b}$ is the number of loans that member $i$ has ever received or the total amount ever borrowed from group $g$ (in branch $b$ ) at midline and endline. Standard errors are clustered at the group level (level of randomization) and the base category is the discussion treatment. As explained above, all endline regressions include sample weights to account for the over-sampling of stayers.

Table 4 shows that the percentage of members that have ever received a loan is equivalent across the treatments with levels of $17 \%$ at midline and $25 \%$ at endline. Similarly, the average number of loans received and the average amount of money borrowed from the group is comparable across treatments: $14 \mathrm{k}$ vs. $15 \mathrm{k}$ UGX borrowed at midline in discussion and vote treatments respectively, and $50 \mathrm{k}$ vs. $46 \mathrm{k}$ UGX at endline. While these results provide evidence that BRAC's program has substantially

increased overall access to financial services between baseline and endline (tripling the 
proportion of borrowers and leading to a six-fold increase in the amount borrowed), the two selection rules appear to have been equally successful at achieving this.

Given our special focus on inclusiveness, we next separately identify the effects for "poor" vs. "less-poor" members:

$$
Y_{i g b}=\alpha_{2}+\beta_{2} \text { Vote }_{g}+\gamma_{2} \text { Poor }_{i}+\delta_{2} \text { Poor }_{i} * \text { Vote }_{g}+\theta_{b}+\varepsilon_{i g b}
$$

where Poor $_{i}$ equals one if member $i$ belongs to the bottom quartile of the group's wealth distribution, as measured with the wealth score. This is our preferred poverty definition as it is the one used by BRAC. In Table A.5, we show that results are robust, although less precise, to defining poverty as belonging to the bottom half of the wealth score distribution or using a continuous measure of poverty (inversely proportional to the wealth score).

Table 4 shows that the composition of people who have been able to borrow from the groups substantially varies across treatments, with poorer members having greater access to loans in the vote treatment than in the discussion treatment. At midline, the poorest members (bottom quartile of their group's wealth distribution) of the discussion groups have indeed received $51 \%$ fewer loans and borrowed $66 \%$ less money than the remaining, richer members. The same pattern is observed at endline, although slightly attenuated: in discussion groups, the poorest members receive $29 \%$ fewer loans and borrow $42 \%$ less money.

The results for savings provide a similar picture. Since the formation of the groups until endline (2011 to 2015), initially poor members in discussion groups saved a total of 106 thousand UGX per person, while initially poor vote group members saved 127 thousand UGX per person. This corresponds to $20 \%$ lower savings among the poor in discussion groups. In comparison to other group members, initially poor members in discussion groups save $10 \%$ less while in the vote treatment they save only $3 \%$ less than others. Taken together, these results indicate that the introduction of a secret vote that selects more representative CMs leads to more inclusive groups. Interestingly, vote groups seem to be more inclusive not only towards the poorest members but also, more generally, towards members who had no loan experience and were hence financially excluded at baseline (Table 4; Columns 3, 6 and 9). Vote groups thus succeeded better in boosting financial inclusion.

In Table A.5b, we estimate whether higher financial inclusion reduces the wealth gap between the most vulnerable group members and the rest. Columns 1-4 compare 
the endline wealth score of two different groups of individuals: those who were in the bottom quartile of their group's distribution at baseline vs the rest. ${ }^{33}$ While the average endline wealth score is comparable across treatments, the gap in the wealth score between the initially poorest members and the rest is almost twice as large in the discussion than in the vote treatment (gap of 6.4 vs. 3.6). Endline dispersion in wealth, as measured with the interquartile range of wealth score and asset value, is lower in vote groups (although some of the coefficients are not precisely estimated). This provides suggestive evidence that the introduction of a secret vote reduces wealth inequality.

\section{Differential dropout or differential loan assignment?}

The finding that poor members receive fewer loans in discussion groups is consistent with two alternative scenarios: (i) Differential dropout: poor members are more likely to exit the groups (ii) Differential loan assignment: poor members are less likely to be granted a loan, conditional on staying in the groups. As the decision to leave the group is endogenous to the actual or perceived benefits from being part of the group, these two channels are not fully separable and are telling the same story: poor members whose group was randomly assigned to the vote treatment benefit more than poor members whose group was randomly assigned to public discussion. The evidence presented in the next two paragraphs suggests that both of these mechanisms are at play.

Differential dropout channel: In discussion groups, initially poor members drop out more than other richer members: they are 7 and 2.6 percentage points less likely to remain in the group at midline and at endline, respectively (although the endline coefficient is not statistically significant). Similarly, members with less initial credit access are 21 percentage points less likely to remain than those with initial loans outside the BRAC group. Meanwhile, in vote groups, the likelihood to stay is the same for initially poor as for richer members, and for members with and without initial loan experience. The retention rate in vote groups is $54.5 \%$ for poor and richer members alike, while only $36 \%$ of initially poor remain at midline in the discussion treatment groups (Table 5, Columns 2 and 5). In other words, poor members are indeed more likely to be pushed out of the groups in the discussion treatment, and this partly explains why they receive fewer loans. In a context with very limited access to financial services, this result has important implications: poor members remain financially more

\footnotetext{
${ }^{33}$ The endline wealth score is computed in the exact same way as the baseline wealth score (Schreiner, 2011).
} 
isolated in discussion than vote groups (more on this below).

Differential loan assignment channel: Table A.6 replicates midline (endline) results restricting the sample to members who are retained at midline (endline). Because we are restricting on a variable that is directly affected by our treatments, this analysis has caveats but remains interesting as it provides suggestive evidence on loan assignment conditional on staying. In discussion groups, "retained" poor members borrow $41 \%$ less money than other members at midline (significant at the $5 \%$ confidence level), while the corresponding difference in vote is $20 \%$ and not statistically significant. By the time of endline, the difference between the treatments has attenuated, and the difference between poor and less poor members is around $45 \%$ (statistically significant only in the discussion treatment). For a more in-depth analysis of whether poor members are excluded in the discussion treatment, one needs to consider the ratio between the proportion of loans assigned to the poor and the proportion of poor members in the group (i.e., the proportion of the retained members who belong to the bottom quartile of the baseline wealth distribution). We will return to this ratio to the next section, and only point out here that the ratio is indeed lower in discussion (0.52) than vote groups (0.97). This indicates that, conditional on "being" a stayer, a poor member is less likely to be given access to loans in discussion groups.

Finally, differences in loan access between poor and richer members across treatments could also be explained by CMs being systematically more likely to assign loans to themselves than to other regular members, irrespective of the treatment. Because elected CMs are poorer in the vote treatment, this would result in a larger proportion of loans given to "poor" members in such groups. We find that such patterns do not fully explain the results: even within the sample of non-CMs, the poorest members receive significantly fewer loans in the discussion treatment (see Table A.7). To further corroborate this, Table A.8 compares access to loans for CMs and non-CMs. While CMs are indeed more likely to assign loans to themselves than to regular group members, this seems to be equally the case in the vote and the discussion treatment. Columns 5-6 of Table A.8 show that, in both vote and discussion groups, CMs remain in the group substantially longer than regular members. Differences in retention across treatments are thus less stark among CMs than among regular members. 


\section{More inclusiveness or lower efficiency?}

While financially excluding the poorest members goes against BRAC guidelines, one possibility is that the CMs elected in discussion groups - who are more educated and potentially more qualified - did not lend to poor members because doing so is inefficient. This would be the case if, for instance, poor members are more likely to default on their loans, or if they are more likely than other members to be given a loan outside the group. Two sets of results suggest that this is not the case. First, endline data on the defaulting behavior of each respondent (Table A.9) shows that poor members are not more likely to default on their loans. (While $10 \%$ of the respondents who have received loans from BRAC reported having fully or partially defaulted at some point, this percentage does not vary across treatments, nor by wealth status). ${ }^{34}$ Similarly, treatment assignment and poverty do not predict the proportion of the total amount borrowed that is not repaid. Second, Table A.10 shows that poor members are not more likely than richer members to get credit outside BRAC, if anything the opposite seems to hold. In a context with very limited access to alternative financial services, ${ }^{35}$ we show that limiting the credit access from these Savings and Loan groups thus translates into lower overall credit access (Column 6).

Providing credit to vulnerable members could also backfire if this increases the chances that "richer" members exit the group, leading to a reduction in group's total savings and cumulative loans (Burlando and Canidio 2017). ${ }^{36}$ We can reject this possibility in our setting: vote groups retain more poor members without reducing the number of less vulnerable members, and thus end up being significantly larger both at midline and at endline (see next section for more details on this). Moreover, as discussed above, group members save and borrow more money on average in the vote than in the discussion treatment (although not significantly more).

\footnotetext{
${ }^{34}$ These data were collected at endline by asking each respondent (a) whether she had ever defaulted on a loan (partially or fully) and (b) the percentage of loans on which she have defaulted. The data was collected from small passbooks in which the respondent is asked to record, each week after the group meeting, the amount she borrows from the group and the total outstanding loan. The proportion of BRAC members who report defaulting (at least partially) on the loan is high (10\%). This is higher than the default rate found in other saving groups in Uganda (e.g., Burlando and Canidio (2017) find a default rate of $3 \%$ ).

${ }^{35}$ Only $15 \%$ of the respondents declare having savings or having a loan from other non-BRAC sources at endline. Among these, $89 \%$ save or borrow money from VSLAs, while none have access to formal banks.

${ }^{36}$ This may happen if these "richer" members do not trust the poor ones to repay or if their main interest in joining the group is credit access (rather than earning an interest on savings).
} 


\subsection{Group-Level Results}

In order to better understand the sustainability of the groups and the inclusiveness of their activities over time, we aggregate individual-level data and examine group-level differences across treatments in Table 6 . We start analyzing retention and member composition; and then move on to aggregate outcomes regarding loan delivery and savings.

\section{Group size and sustainability}

While groups in both treatments start out similar in size, the vote ones end up being statistically larger. Retention rate is indeed larger in the vote than in the discussion treatment: $54 \%$ vs. $41 \%$ at midline and 26 vs. $21 \%$ at endline (Table 6, Columns 1 and 4). ${ }^{37}$ Vote groups are also more sustainable, i.e., they are less likely to have "collapsed" by losing all their members. At midline, about $1 \%$ of vote groups had lost all their member vs. $15 \%$ in the discussion treatment. This difference had converged by the time of the endline survey with a $20 \%$ collapse rate in both treatments (Columns 2 and $5)$.

Groups also differ in member composition, with vote ones retaining proportionally more poor members. Here, individuals who initially belonged to the bottom quartile of the distribution end up representing $28 \%$ and $32 \%$ of the whole group at midline and endline, respectively. In contrast, in the discussion treatment, their share falls to $21 \%$ at midline and $19 \%$ at endline (Table 6, Columns 3 and 6 ). Differences in member composition across treatments thus seem to increase over time and do not attenuate. Further evidence of the change in group size and composition over time is shown in Figure A.1 where we plot the kernel density of the number of poor members over time and across treatments.

\section{Group-level allocation of loans}

Table 6 (Columns 7-11) compares the proportion of loans assigned to poor vs. less-poor members across treatments. In discussion groups, poor members comprise $19 \%$ of their groups and are assigned $12.2 \%$ of the total loan number by endline (Column 9). In vote groups, they instead comprise $32 \%$ of their groups and are assigned $29.3 \%$ of the

\footnotetext{
${ }^{37}$ The small discrepancy between the retention shares on the aggregate level and the individual level retention shares (Table 5) is explained by the fact that before collapsing data at the group level, 75 individuals for whom we have no poverty status data from baseline were dropped from the sample.
} 
total loan number (Column 9). The ratio between the proportion of loans assigned to the poor and the proportion of poor members is thus smaller in discussion groups: $64 \%$ $(=12.2 / 19)$ vs. $92 \%(=29.3 / 32)$ in vote groups. Finally, conditional on remaining in the group, poor members save almost twice as much money in the vote than in the discussion treatment (Column 11, Panel B). This provides further evidence that vote groups are indeed more inclusive towards vulnerable members.

\subsection{Leader Types and Treatment effects}

This section shows that the individual and group-level differences highlighted so far are most likely explained by a leader selection effect (i.e., the fact that selection rules affect the type of leaders selected), rather than by other mechanisms through which the treatments may affect group outcomes independently of leader types.

The first piece of evidence is presented in Table A.11. This table shows that CMs characteristics strongly correlate with group outcomes: committees with at least one "poor" member (vs. none) more than doubles the percentage of loans assigned to the poor (Column 2). Education instead reduces pro-poor targeting substantially: committees with at least one highly educated member reduces the proportion of loans assigned to the poor by a factor of two (Column 2). The results hold regardless of whether we consider the average committee characteristics (percentage of CMs who are poor or educated) or the median characteristic (whether at least half of the members are poor or educated). ${ }^{38}$

Rather than through leader selection, our treatments could also potentially affect group outcomes if one of the two procedures is perceived as more legitimate. This would indeed lead to higher member satisfaction and involvement (and hence lower dropout) in one of the two treatments, holding leader type constant. To examine this possibility we use data collected at the time of the endline survey on perceived legitimacy. We interviewed two samples of respondents (1) Group Members: our regular endline respondents (who had been present at the leader selection 3 years earlier), (2) Non-Group Members: a random subsample of 400 women who were all enrolled in the local BRAC youth center at endline but had not been members of the Loans and Saving group when leader selection took place. In both samples, our interviewers

\footnotetext{
${ }^{38}$ This is not reported in the table due to space constraints but available upon request. Results also hold, and become stronger, if the independent variable is whether "all" members of the committee are poor or educated.
} 
described to the respondents both selection procedures and asked them which of the two they perceive as more fair. ${ }^{39}$ We use data from Non-Group Members to proxy for the attitude towards the decision rules ex-ante (before going through the decision process) and data from Group Members to pick up differences in perceived legitimacy ex-post (after observing how the decision making unfolded). The sample of Group Members were also asked whether they were satisfied with the way CMs had been elected in their own group.

We find no support for the legitimacy channel. The secret vote is perceived as the most fair procedure for $43 \%$ of the Non-Group Members and $40 \%$ of the Group Members (see Table A12). This illustrates a lack of consensus on which procedure is the most legitimate with diverging opinions across individuals. On average, it seems that the open discussion is perceived as slightly more legitimate in both samples. Also, $88 \%$ of the Group Members reported being satisfied with the way leaders were elected in their group. Importantly, perceived legitimacy does not differ significantly across treatments, nor does it differ between richer and poorer group members (this is true both acrossand within-treatments). Differential perceived legitimacy is thus unlikely to explain the differences observed in section 6.1 between poor and less poor group members, and those observed in 6.2 on differential aggregate dropout. ${ }^{4041}$

\section{Conclusion}

This paper estimates the causal effect of leader selection rules on group governance and service delivery. Ninety-two Savings and Loan groups created through a poverty

\footnotetext{
${ }^{39}$ Both selection procedures were described to the respondents as "two ways of choosing leaders for a group," and respondents were then asked "Which of the 2 ways of choosing do you find more fair (without bias)?" We asked this question at endline rather than at baseline because we were worried that our questions could become an intervention by itself: asking about perception of a rule before the election took place could have by itself affected electoral outcomes.

${ }^{40}$ This result reflects the fact that our respondents have little or no experience of being active participants in either one of the two decision making procedures. It is likely that they cannot imagine how the electoral procedure unfolds without going through it in practice, and this would explain why we see no difference across richer and poorer members. The results suggest that no societal consensus exists in this context regarding which electoral rule leads to the best aggregate outcomes. This interpretation is also supported by the fact that local BRAC staff that implemented the selection procedures in the groups expressed in informal conversations with the research team that they did not think the election rule could matter for the outcome.

${ }^{41}$ Visibility (which can impact reciprocity) is unlikely to explain our results. Both treatments involve a public discussion (in the vote treatment, a non binding discussion takes place before the private vote) and hence leaders in both discussion and vote treatments may have tilted loan allocation towards members who openly supported them (and away from those who openly opposed them).
} 
alleviation program were randomly assigned to chose their committees either publicly or in a secret ballot vote.

We find that the way leaders are selected affects both leader types and group services. The secret vote procedure generates more representative leaders, while the public discussion procedure results in leaders that are positively selected in terms of education and training. Furthermore, the introduction of a secret vote - under which more representative but less educated leaders are selected - creates groups that are more inclusive towards poor members. In our context, this shows up by vote groups displaying a higher retention rate among poor members, a higher share of loans being allocated to poor members and higher saving levels among the poor in the group.

The more inclusive access to savings and credit in vote groups is not accompanied by lower efficiency: default rates on loans are similar across treatments, and there is no deterioration of the savings or lending activity in vote groups. Vote groups are also significantly less likely than discussion groups to collapse during the first year following leader selection. Overall, our findings point to the benefit of finding electoral rules that minimize elite capture, even if it comes at the expense of leader qualifications. Moreover, the observation that introducing a secret vote and resulting changes in governance can increase short-run sustainability may provide a first step toward a solution of the welldocumented problem of low sustainability of development programs (Mansuri and Rao 2012; Fishman et al. 2017).

To the best of our knowledge, this paper is the first to provide experimental evidence on the causal effects of electoral rules in group settings. As with most experimental work, internal validity is achieved within a specific context, and this may raise questions about the external validity of our results. Beyond its direct relevance for the many development programs that involve community based groups, we believe that our study provides broader lessons for public policy in developing countries, complementing research about the effect of political selection on service delivery.

Specifically, our study can inform the selection of local delivery agents who provide members of their own communities with specific services (for instance within health and agricultural extension). Our results suggest that the way in which such agents are selected may result in a different "type" of agent recruited and can affect service delivery and outreach. They also indicate that the success of "community driven development" projects, which consists in involving the community in decisions about public services, hinges on the method of decision making. In fact, community involvement using an inadequate decision making rule could lead to worse outcomes than having an NGO 
or the Government making decisions without community participation, especially in situations where there is risk of elite capture at the local level.

\section{References}

Alatas, V., A. Banerjee, R. Hanna, B.A. Olken, and J. Tobias, "Targeting the poor: evidence from a field experiment in Indonesia," The American economic review, 2012, 102 (4), 1206-1240.

Alesina, Alberto and Eliana La Ferrara, "Who trusts others?," Journal of public economics, 2002, 85 (2), 207-234.

Ashraf, Nava, Oriana Bandiera, Scott S Lee et al., "Do-gooders and go-getters: career incentives, selection, and performance in public service delivery," Working Paper, 2016.

Baird, Sarah J, Craig McIntosh, and Berk Özler, "The regressive demands of demand-driven development," Journal of Public Economics, 2013, 106, 27-41.

Baland, Jean-Marie and James A Robinson, "Land and power: Theory and evidence from Chile," The American Economic Review, 2008, 98 (5), 1737-1765.

_ , Rohini Somanathan, and Lore Vandewalle, "Socially Disadvantaged Groups and Microfinance in India," Working Paper, 2015.

Bandiera, Oriana, Robin Burgess, Erika Deserranno, and Imran Rasul, "Social connections and the delivery of development programs," Working paper, 2017.

_, _, Markus Goldstein, Niklas Buehren, Selim Gulesci, Imran Rasul, and Munshi Sulaiman, "Women's empowerment in action: evidence from a randomized control trial in Africa," Working Paper, 2014.

Banerjee, Abhijit, Arun G Chandrasekhar, Esther Duflo, and Matthew O Jackson, "The diffusion of microfinance," Science, 2013, 341 (6144), 1236498.

_ , Esther Duflo, Raghabendra Chattopadhyay, and Jeremy Shapiro, "Targeting Efficiency: How well can we identify the poorest of the poor?," Working Paper, 2009.

Bardhan, Pranab and Dilip Mookherjee, "Pro-poor targeting and accountability of local governments in West Bengal," Journal of development Economics, 2006, 79 (2), 303-327. 
Beaman, Lori, Ariel BenYishay, and Jeremy Magruder Ahmed Mushfiq Mobarak, "Can Network Theory based Targeting Increase Technology Adoption?," Working Paper, 2014.

Beath, Andrew, Fotini Christia, and Ruben Enikolopov, "Direct democracy and resource allocation: Experimental evidence from Afghanistan," Journal of Development Economics, 2017, 124, 199-213.

_, _, Georgy Egorov, and Ruben Enikolopov, "Electoral rules and political selection: theory and evidence from a field experiment in Afghanistan," The Review of Economic Studies, 2016, 83 (3), 932-968.

BenYishay, Ariel and A Mushfiq Mobarak, "Social Learning and Incentives for Experimentation and Communication," Working paper, 2015.

Besley, Timothy, "Political selection," The Journal of Economic Perspectives, 2005, 19 (3), 43-60.

- and Stephen Coate, "An economic model of representative democracy," The Quarterly Journal of Economics, 1997, 112 (1), 85-114.

_, Rohini Pande, and Vijayendra Rao, "Participatory democracy in action: Survey evidence from South India," Journal of the European Economic Association, 2005, $3(2-3), 648-657$.

Björkman, Martina and Jakob Svensson, "When is community-based monitoring effective? Evidence from a randomized experiment in primary health in Uganda," Journal of the European Economic Association, 2010, 8 (2-3), 571-581.

Burlando, Alfredo and Andrea Canidio, "Does group inclusion hurt financial inclusion? Evidence from ultra-poor members of Ugandan savings groups," Journal of Development Economics, 2017, 128, 24-48.

Cox, Gary W, Making votes count: strategic coordination in the world's electoral systems, Cambridge University Press, 1997.

Czuba, Karol, "Even if I have land, Can I eat it?," BRAC Report, 2011.

_, "Income Generating Activities and Savings Behaviour of Adolescent Girls and Young Women in Karamoja," 2012.

Deserranno, Erika, "Financial incentives as signals: Experimental evidence from the recruitment of health promoters in Uganda," Working paper, 2017.

Dupas, Pascaline and Jonathan Robinson, "Savings constraints and microenterprise development: Evidence from a field experiment in Kenya," American Economic Journal: Applied Economics, 2013a, 5 (1), 163-192. 
_ and _, "Why don't the poor save more? Evidence from health savings experiments," The American Economic Review, 2013b, 103 (4), 1138-1171.

Fishman, Ram, Stephen C Smith, Vida Bobić, and Munshi Sulaiman, "How Sustainable Are Benefits from Extension for Smallholder Farmers? Evidence from a Randomized Phase-Out of the BRAC Program in Uganda," Working Paper, 2017.

Galasso, Emanuela and Martin Ravallion, "Decentralized targeting of an antipoverty program," Journal of Public economics, 2005, 89 (4), 705-727.

Grossman, Guy, "Do selection rules affect leader responsiveness? Evidence from rural Uganda," Quarterly Journal of Political Science, 2014, 9 (1), 1-44.

Hinnerich, Björn Tyrefors and Per Pettersson-Lidbom, "Democracy, redistribution, and political participation: Evidence from Sweden 1919-1938," Econometrica, 2014, $82(3), 961-993$.

Huber, Evelyne, Charles Ragin, and John D Stephens, "Social democracy, Christian democracy, constitutional structure, and the welfare state," American journal of Sociology, 1993, 99 (3), 711-749.

Humphreys, Macartan, William A Masters, and Martin E Sandbu, "The role of leaders in democratic deliberations: results from a field experiment in São Tomé and Príncipe," World Politics, 2006, 58 (04), 583-622.

Madajewicz, Malgosia, Anna Tompsett, and Ahasan Habib, "Community Participation in Decision-Making Evidence from an experiment in safe drinking water provision in Bangladesh," Working paper, 2017.

Mansuri, Ghazala and Vijayendra Rao, Localizing development: does participation work?, World Bank Publications, 2012.

Niehaus, Paul and Antonia Atanassova, "Targeting with agents," American Economic Journal: Economic Policy, 2013, 5 (1), 206-238.

Olken, Benjamin A, "Direct democracy and local public goods: Evidence from a field experiment in Indonesia," American political science review, 2010, 104 (02), 243-267.

Osborne, Martin J and Al Slivinski, "A model of political competition with citizencandidates," The Quarterly Journal of Economics, 1996, 111 (1), 65-96.

Persson, Torsten and Guido Enrico Tabellini, Political economics: explaining economic policy, MIT press, 2002.

_ and _, The economic effects of constitutions, MIT press, 2005.

Pitkin, Hanna Fenichel, The concept of representation, Univ of California Press, 1967. 
Schreiner, Mark, "A simple poverty scorecard for Uganda," BRAC Report, 2011, 15, 2013.

Sulaiman, Munshi, "Poverty scorecard for monitoring progress against dollar-a-day in Uganda," BRAC Report, 2014. 


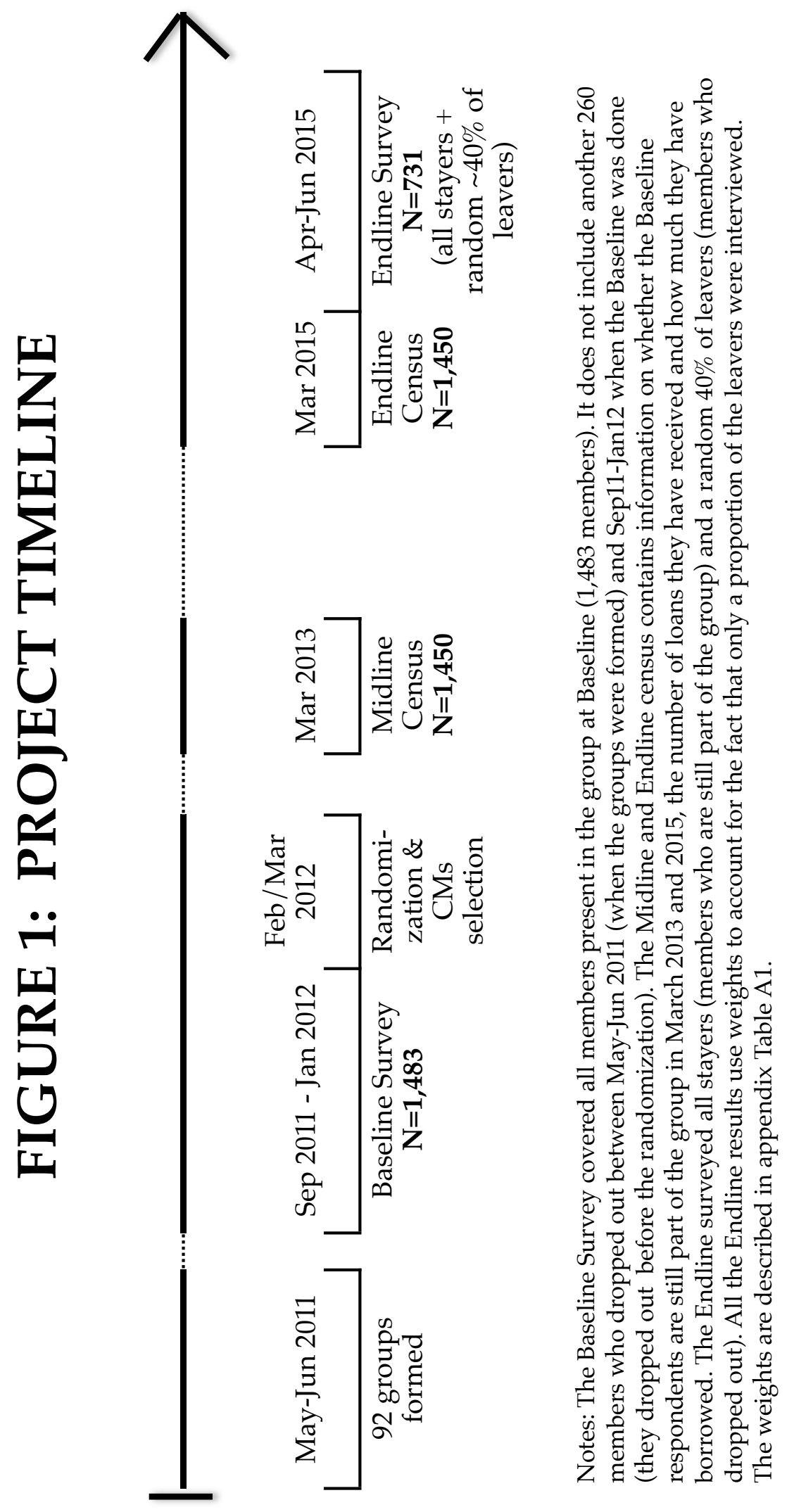




\section{FIGURE 2: POSITION IN THE GROUP WEALTH DISTRIBUTION, COMMITTEE MEMBERS VS. NON-COMMITTEE MEMBERS}

\section{Panel A: Wealth score}

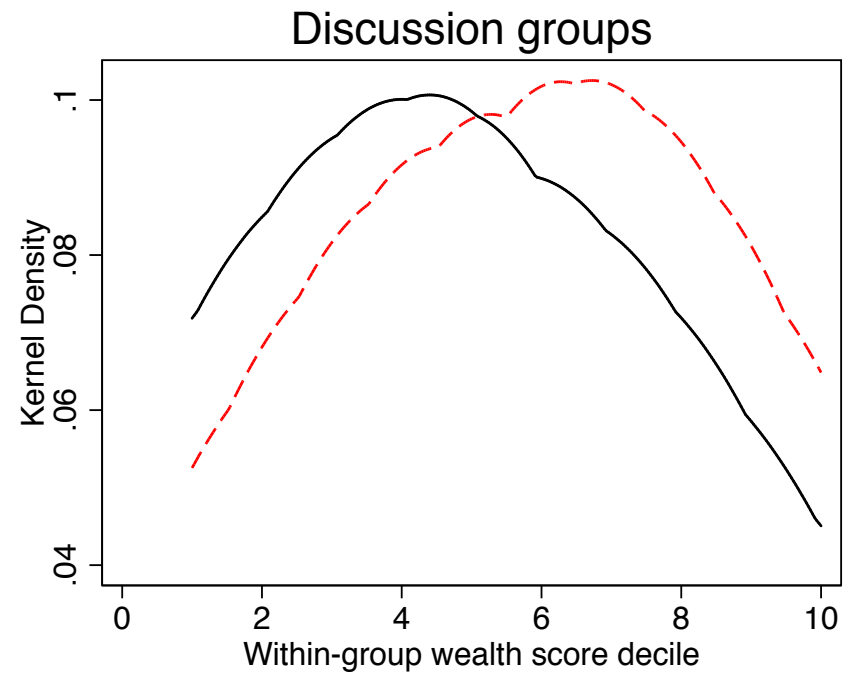

Non-Committee - - - - Committee

Kolmogorov-Smirnov equality-of-distributions test: p-value $=0.010$

\section{Panel B: Value of assets owned}

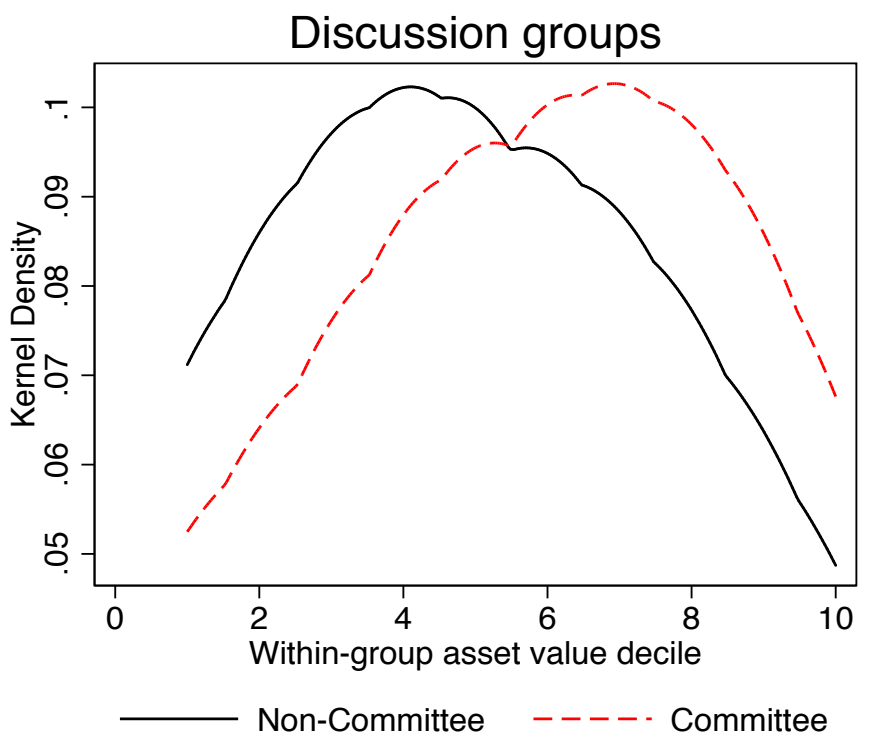

Kolmogorov-Smirnov equality-of-distributions test: $\mathrm{p}$-value $=0.009$

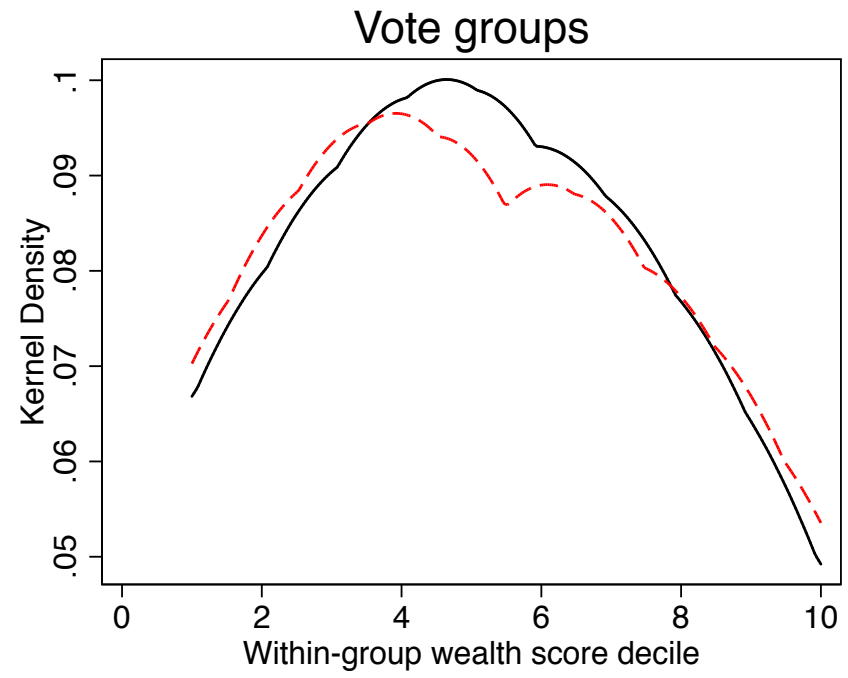

Non-Committee - - - - Committee

Kolmogorov-Smirnov equality-of-distributions test: $\mathrm{p}$-value $=0.498$

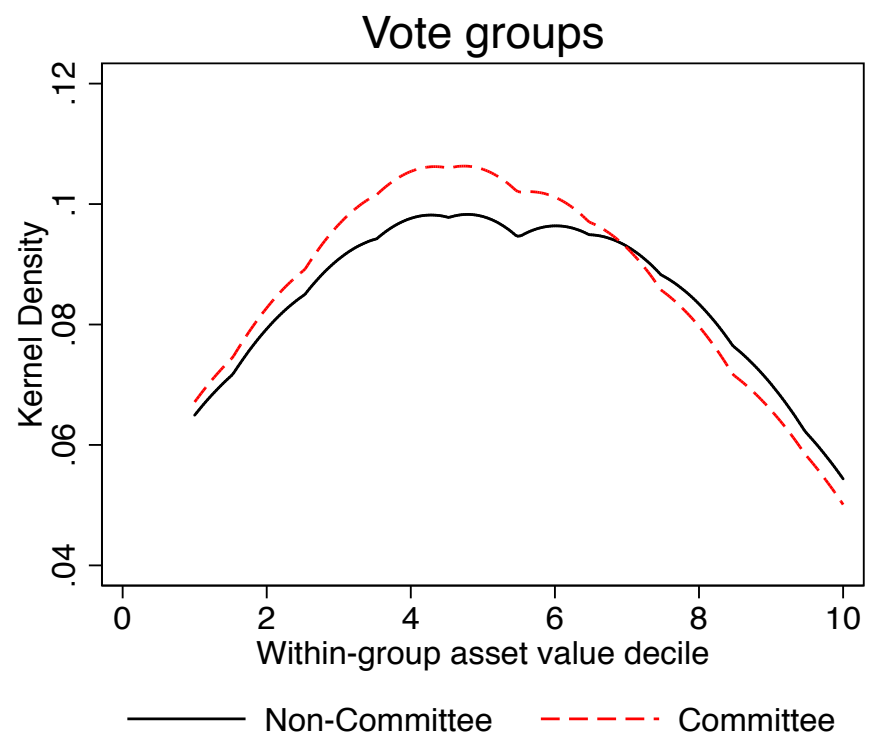

Kolmogorov-Smirnov equality-of-distributions test: $\mathrm{p}$-value $=0.920$

Note: I his tigure shows the "wealth score" and "asset value" distribution at baseline separately tor regular members (non-committee members) and committee members, by treatment. The x-axis indicates the position (decile) of an individual in the wealth (Panel A) or asset (Panel B) distribution of her group. Higher value=less poor. Kernel density plot; Epanechikov Kernel. The p-values of the Kolmogorov-Smirnov tests of equality of distributions (non-committee members vs. committee members) are reported at the bottom of the each figure. "Wealth score" is a score from 0 to 100 based on a scale constructed by Grameen Foundation to measure wealth in Uganda. "Assets value" is the value of total assets (household, agriculture and business) owned by the respondent's household, in millions of UGX. 

(1)
(2)
(3)
(4)
(5)
(6)
Obs Mean S.D.
Mean in Mean in
p-value
Treatm. Treatm.
Vote $=$ Disc.

\section{(A) Group variables}

Number of group members

92

$16.47 \quad 5.70$

16.26

16.07

0.86

(B) Member variables

\section{Basic characteristics}

Age

Married

Has children

Is a student

Is working

Conditional on working...

Main working activity is 'agriculture/animal husbandry'

Main working activity is 'non-agriculture business'

Main working activity is 'agriculture casual day work'

Main working activity is 'non-agriculture casual day work'

\begin{tabular}{|c|c|c|c|c|c|}
\hline 1459 & 21.65 & 7.92 & 21.95 & 21.35 & 0.49 \\
\hline 1462 & 0.59 & 0.49 & 0.62 & 0.56 & 0.36 \\
\hline 1408 & 0.61 & 0.49 & 0.65 & 0.56 & 0.11 \\
\hline 1463 & 0.21 & 0.40 & 0.19 & 0.22 & 0.50 \\
\hline 1483 & 0.79 & 0.41 & 0.80 & 0.78 & 0.60 \\
\hline 1175 & 0.26 & 0.44 & 0.26 & 0.26 & 0.90 \\
\hline 1175 & 0.47 & 0.50 & 0.48 & 0.46 & 0.77 \\
\hline 1175 & 0.12 & 0.33 & 0.12 & 0.13 & 0.79 \\
\hline 1175 & 0.15 & 0.35 & 0.14 & 0.15 & 0.83 \\
\hline 1414 & 0.83 & 0.37 & 0.84 & 0.83 & 0.80 \\
\hline 1423 & 0.00 & 0.00 & 0.00 & 0.00 & - \\
\hline 1414 & 0.01 & 0.12 & 0.01 & 0.02 & 0.55 \\
\hline 1414 & 0.03 & 0.17 & 0.02 & 0.04 & 0.57 \\
\hline 1345 & 17.07 & 34.16 & 17.75 & 16.43 & 0.65 \\
\hline 1423 & 0.00 & 0.00 & 0.00 & 0.00 & - \\
\hline 1423 & 0.00 & 0.00 & 0.00 & 0.00 & - \\
\hline 1310 & 0.12 & 0.33 & 0.11 & 0.13 & 0.56 \\
\hline 1297 & 8.12 & 40.82 & 7.20 & 9.02 & 0.64 \\
\hline 1449 & 25.70 & 17.75 & 23.99 & 27.44 & 0.13 \\
\hline 1467 & 2.70 & 6.19 & 2.53 & 2.87 & 0.54 \\
\hline 1463 & 0.50 & 0.50 & 0.51 & 0.48 & 0.57 \\
\hline 1463 & 0.23 & 0.42 & 0.26 & 0.21 & 0.19 \\
\hline 1414 & 0.25 & 0.43 & 0.20 & 0.29 & 0.19 \\
\hline 1483 & 0.29 & 0.45 & 0.29 & 0.29 & 0.99 \\
\hline 1370 & 0.31 & 0.46 & 0.31 & 0.30 & 0.82 \\
\hline 1483 & 0.44 & 0.50 & 0.44 & 0.44 & 0.97 \\
\hline 1483 & 0.10 & 0.11 & 0.10 & 0.11 & 0.52 \\
\hline
\end{tabular}

Savings and loans

Has savings in BRAC group

Has savings in a Bank, MFI or a VSLA

Has savings in a SACCO

Has savings at home or with a person

Total amount saved (in thousand UGX)

Has a loan from BRAC group

Has a loan from a Bank, MFI or VSLA

Has a loan from a person

Total amount borrowed (in thousand UGX)

Wealth measures

Wealth score (0 to 100)

Value of assets owned (in mln UGX)

\section{Education/ Training}

Has ever enrolled in school

Has completed primary school

Has participated in business training

Has received advice on earning activies in the past year

\section{Social connections and background}

Has worked/studied outside village for at least a year

Does not belong to majority tribe

Share of group members who are close friends

$\begin{array}{lll}0.10 & 0.11 \quad 0.10\end{array}$

0.44
0.11

0.97
0.52

Notes: Columns 2-3 show means and standard deviations in the whole sample. Columns 4 and 5 show means in the Vote and the Discussion Treatment separately. Column 6 reports the p-value of the test of equality of means based on robust standard errors clustered at the group level (level of randomization). "Is a student" equals 1 if the respondent is currently in school. "Main working activity" is defined as the most time-consuming earning activity the respondent is engaged in. "Wealth score" is a score from 0 to 100 based on a scale constructed by Grameen Foundation to measure wealth in Uganda (higher values indicate higher wealth). See Schreiner (2011) for details on how the score is calculated. "Assets value" is the total value of assets (household, agriculture and business assets) owned by the respondent's household, in millions of UGX and truncated at the top $1 \%$ to clean for outliers. "Has participated in business training" equals 1 if the respondent has ever participated in a training on business skills and/or financial literacy, offered by BRAC or other providers. "Share of group members who are close friends" is a normalized degree centrality measure. For group member $X$, this is the percentage of members in the group who reports $X$ as being among the 2 best friends in the group at Baseline. The number of observations vary across variables due to the presence of missing values. 


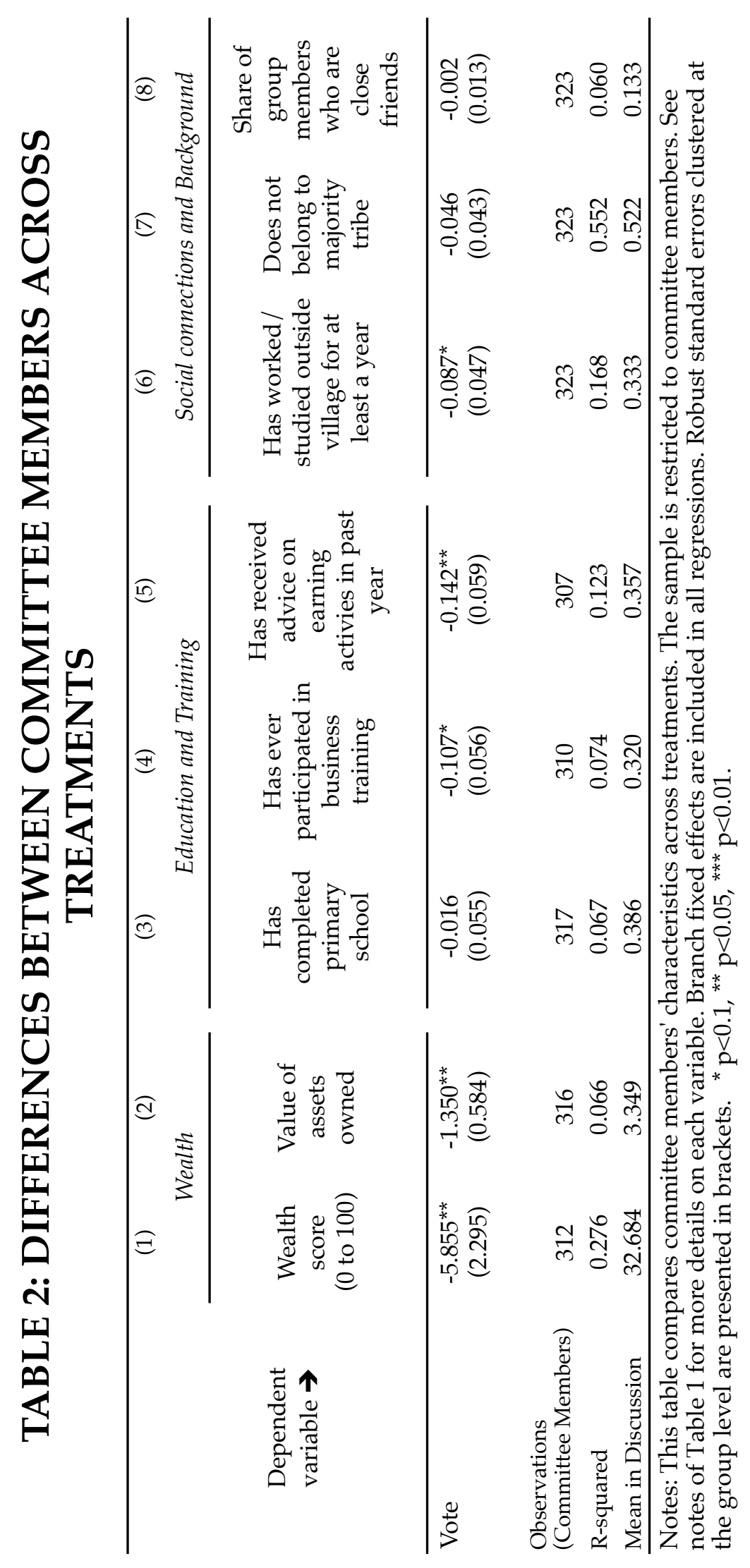




\section{TABLE 3: DIFFERENCES BETWEEN COMMITTEE AND NON-COMMITTEE MEMBERS, ACROSS TREATMENTS}

\section{Panel A: Wealth Score and Asset Value}

(1)

Dependent Variable $\rightarrow$

\begin{tabular}{|c|c|c|c|c|c|c|c|c|c|c|}
\hline \multirow{2}{*}{ TRAIT (at Baseline) $\rightarrow$} & \multirow{2}{*}{$\begin{array}{c}\text { Wealth } \\
\text { score } \\
(0 \text { to } 100)\end{array}$} & \multicolumn{4}{|c|}{$=1$ if wealth score is $[\ldots]$} & \multirow{2}{*}{$\begin{array}{l}\text { Value of } \\
\text { assets } \\
\text { owned }\end{array}$} & \multicolumn{4}{|c|}{$=1$ if asset value is $[. .]}$. \\
\hline & & $\begin{array}{l}<25 \% \\
\text { pctile }\end{array}$ & $\begin{array}{l}25 \text { to } 50 \% \\
\text { pctile }\end{array}$ & $\begin{array}{l}50 \text { to } \\
75 \% \\
\text { pctile }\end{array}$ & $\begin{array}{l}>75 \% \\
\text { pctile }\end{array}$ & & $\begin{array}{l}<25 \% \\
\text { pctile }\end{array}$ & $\begin{array}{l}25 \text { to } 50 \% \\
\text { pctile }\end{array}$ & $\begin{array}{l}50 \text { to } \\
75 \% \\
\text { pctile }\end{array}$ & $\begin{array}{l}>75 \% \\
\text { pctile }\end{array}$ \\
\hline Vote & $\begin{array}{c}0.045 \\
(0.033)\end{array}$ & $\begin{array}{l}-0.026 \\
(0.021)\end{array}$ & $\begin{array}{c}0.007 \\
(0.020)\end{array}$ & $\begin{array}{c}0.007 \\
(0.017)\end{array}$ & $\begin{array}{c}0.026 \\
(0.019)\end{array}$ & $\begin{array}{c}0.022 \\
(0.017)\end{array}$ & $\begin{array}{c}0.004 \\
(0.020)\end{array}$ & $\begin{array}{l}-0.026 \\
(0.019)\end{array}$ & $\begin{array}{c}0.026 \\
(0.019)\end{array}$ & $\begin{array}{c}0.022 \\
(0.020)\end{array}$ \\
\hline TRAIT & $\begin{array}{c}0.003^{* * *} \\
(0.001)\end{array}$ & $\begin{array}{c}-0.092^{* * *} \\
(0.034)\end{array}$ & $\begin{array}{l}-0.002 \\
(0.034)\end{array}$ & $\begin{array}{c}-0.010 \\
(0.033)\end{array}$ & $\begin{array}{c}0.138^{* * *} \\
(0.042)\end{array}$ & $\begin{array}{c}0.003 \\
(0.003)\end{array}$ & $\begin{array}{c}-0.032 \\
(0.032)\end{array}$ & $\begin{array}{c}-0.097^{* * *} \\
(0.034)\end{array}$ & $\begin{array}{l}0.096^{* *} \\
(0.039)\end{array}$ & $\begin{array}{c}0.036 \\
(0.037)\end{array}$ \\
\hline Vote * TRAIT & $\begin{array}{c}-0.001 \\
(0.001)\end{array}$ & $\begin{array}{l}0.095^{* *} \\
(0.044)\end{array}$ & $\begin{array}{l}-0.011 \\
(0.050)\end{array}$ & $\begin{array}{c}-0.011 \\
(0.049)\end{array}$ & $\begin{array}{l}-0.108^{*} \\
(0.058)\end{array}$ & $\begin{array}{l}-0.006^{*} \\
(0.003)\end{array}$ & $\begin{array}{c}0.005 \\
(0.045)\end{array}$ & $\begin{array}{c}0.147^{* * *} \\
(0.049)\end{array}$ & $\begin{array}{c}-0.080 \\
(0.055)\end{array}$ & $\begin{array}{l}-0.073 \\
(0.050)\end{array}$ \\
\hline Observations (Members) & 1,449 & 1,449 & 1,449 & 1,449 & 1,449 & 1,467 & 1,467 & 1,467 & 1,467 & 1,467 \\
\hline R-squared & 0.025 & 0.022 & 0.017 & 0.017 & 0.026 & 0.020 & 0.019 & 0.024 & 0.023 & 0.019 \\
\hline Mean dep var in Discussion & 0.220 & 0.220 & 0.220 & 0.220 & 0.220 & 0.220 & 0.220 & 0.220 & 0.220 & 0.220 \\
\hline Mean dep var in Discussion \& NO-TRAIT & - & 0.214 & 0.219 & 0.221 & 0.210 & - & 0.224 & 0.207 & 0.214 & 0.226 \\
\hline Coeff (TRAIT + Vote* TRAIT) & 0.002 & 0.004 & -0.013 & -0.021 & 0.030 & -0.002 & -0.027 & 0.050 & 0.016 & -0.037 \\
\hline p-value (TRAIT + Vote* TRAIT) & 0.061 & 0.898 & 0.728 & 0.564 & 0.451 & 0.057 & 0.396 & 0.161 & 0.671 & 0.287 \\
\hline
\end{tabular}

(2)

(3)

(4)

(5)

(6)

(7)

(8)

$(9)$

$(10)$

$=1$ if member becomes committee member, and 0 otherwise

\section{Panel B: Education, Training and Others}

(2)

(3)

(4)

(5)

Dependent Variable $\rightarrow$

$=1$ if member becomes committee member, and 0 otherwise

Has ever

TRAIT (at Baseline)

Has completed primary school
Has ever participated in business training
Has received advice on earning activies in the past year
Has worked or studied outside the village for at least 1 year
Does not belong to majority tribe
Share of group members who are close friends

\begin{tabular}{|c|c|c|c|c|c|c|}
\hline \multirow[t]{2}{*}{ Vote } & 0.019 & 0.005 & 0.020 & $0.038^{*}$ & $0.045^{* *}$ & -0.018 \\
\hline & $(0.019)$ & $(0.021)$ & $(0.020)$ & $(0.020)$ & $(0.021)$ & $(0.022)$ \\
\hline \multirow[t]{2}{*}{ TRAIT } & $0.232^{* * *}$ & 0.068 & $0.098^{* * *}$ & 0.042 & 0.036 & $0.939^{* * *}$ \\
\hline & $(0.048)$ & $(0.046)$ & $(0.034)$ & $(0.032)$ & $(0.037)$ & $(0.185)$ \\
\hline \multirow[t]{2}{*}{ Vote ${ }^{*}$ TRAIT } & $-0.113^{*}$ & 0.015 & -0.048 & $-0.136^{* * *}$ & $-0.088^{* *}$ & 0.370 \\
\hline & $(0.062)$ & $(0.055)$ & $(0.043)$ & $(0.048)$ & $(0.037)$ & $(0.249)$ \\
\hline Observations (Members) & 1,463 & 1,414 & 1,483 & 1,370 & 1,483 & 1,483 \\
\hline R-squared & 0.050 & 0.025 & 0.023 & 0.022 & 0.020 & 0.089 \\
\hline Mean dep var in Discussion & 0.220 & 0.22 & 0.220 & 0.220 & 0.224 & 0.220 \\
\hline Mean dep var in Discussion \& NO-TRAIT & 0.189 & 0.210 & 0.247 & 0.221 & 0.220 & 0.111 \\
\hline Coeff (TRAIT + Vote* TRAIT) & 0.119 & 0.082 & 0.050 & -0.095 & -0.052 & 1.309 \\
\hline p-value (TRAIT + Vote* TRAIT) & 0.003 & 0.070 & 0.133 & 0.013 & 0.212 & 0.000 \\
\hline
\end{tabular}

Notes: The table estimates which TRAIT predicts "becoming a committee member" and whether the predictive power of each TRAIT varies across treatments. The dependent variable is a dummy that equals 1 if a group member becomes a committee member. TRAIT is a Baseline characteristic of a group member. Panel A: "Wealth score" is a score from 0 to 100 based on a scale constructed by Grameen Foundation to measure wealth in Uganda (Higher values indicate higher wealth). "Assets value" is the total value of assets (household, agriculture and business assets) owned by the respondent's household, in millions of UGX and truncated at the top 1\% to clean for outliers. Columns 2-5 and 7-10 examine heterogenous effects depending on a member's position of her group's distribution. Panel B: See notes of Table 1 for more details on each variable. All regressions include branch fixed effects. Robust standard errors clustered at the group level are presented in brackets. ${ }^{*} \mathrm{p}<0.1,{ }^{* *} \mathrm{p}<0.05,{ }^{* * *} \mathrm{p}<0.01$. 


\section{TABLE 4: TREATMENT EFFECTS ON LOANS AND SAVINGS}

\begin{tabular}{|c|c|c|c|c|c|c|c|c|c|c|c|c|}
\hline \multirow{4}{*}{$\begin{array}{l}\text { Dependent Variable } \rightarrow \\
\text { TRAIT (at Baseline) } \rightarrow\end{array}$} & (1) & (2) & (3) & (4) & (5) & (6) & (7) & (8) & (9) & & & \\
\hline & \multicolumn{9}{|c|}{ Panel A: Midline Results (2013) } & & & \\
\hline & \multicolumn{3}{|c|}{$\begin{array}{l}=1 \text { if received a loan in } \\
\text { the past year from BRAC } \\
\text { group }\end{array}$} & \multicolumn{3}{|c|}{$\begin{array}{l}\text { \# loans received in the } \\
\text { past year from BRAC } \\
\text { group }\end{array}$} & \multicolumn{3}{|c|}{$\begin{array}{l}\text { Amount borrowed in the } \\
\text { past year from BRAC group }\end{array}$} & & & \\
\hline & - & Poor & $\begin{array}{c}\text { Has no } \\
\text { loan }\end{array}$ & - & Poor & $\begin{array}{c}\text { Has no } \\
\text { loan }\end{array}$ & - & Poor & $\begin{array}{l}\text { Has no } \\
\text { loan }\end{array}$ & & & \\
\hline Vote & \multirow[t]{3}{*}{$\begin{array}{c}0.005 \\
(0.039)\end{array}$} & $\begin{array}{l}-0.008 \\
(0.039)\end{array}$ & $\begin{array}{l}-0.174 \\
(0.106)\end{array}$ & $\begin{array}{l}-0.030 \\
(0.060)\end{array}$ & $\begin{array}{l}-0.071 \\
(0.062)\end{array}$ & $\begin{array}{c}-0.385^{* *} \\
(0.182)\end{array}$ & \multirow[t]{3}{*}{$\begin{array}{c}0.977 \\
(4.770)\end{array}$} & $\begin{array}{l}-2.222 \\
(5.784)\end{array}$ & $\begin{array}{c}-6.213 \\
(12.118)\end{array}$ & & & \\
\hline TRAIT & & $\begin{array}{c}-0.051^{* *} \\
(0.025)\end{array}$ & $\begin{array}{c}-0.189^{* *} \\
(0.086)\end{array}$ & & $\begin{array}{c}-0.145^{* * *} \\
(0.045)\end{array}$ & $\begin{aligned} * & -0.382^{* *} \\
& (0.165)\end{aligned}$ & & $\begin{array}{c}-11.133^{* *} \\
(4.533)\end{array}$ & $\begin{array}{r}-14.783^{*} \\
(7.894)\end{array}$ & & & \\
\hline Vote * TRAIT & & $\begin{array}{c}0.045 \\
(0.041)\end{array}$ & $\begin{array}{l}0.201^{* *} \\
(0.098)\end{array}$ & & $\begin{array}{l}0.120^{* *} \\
(0.060)\end{array}$ & $\begin{array}{l}0.395^{\star *} \\
(0.170)\end{array}$ & & $\begin{array}{c}9.085 \\
(5.735)\end{array}$ & $\begin{array}{c}9.425 \\
(10.852)\end{array}$ & & & \\
\hline Observations (Members) & 1,427 & 1,394 & 1,260 & 1,445 & 1,411 & 1,278 & 1,365 & 1,334 & 1,210 & & & \\
\hline R-squared & 0.074 & 0.072 & 0.077 & 0.080 & 0.079 & 0.091 & 0.039 & 0.045 & 0.049 & & & \\
\hline Mean dep var in Discussion & 0.174 & 0.174 & 0.174 & 0.250 & 0.250 & 0.250 & 14.018 & 14.018 & 14.018 & & & \\
\hline Mean dep var in Disc. \& NO-TRAIT & & 0.183 & 0.349 & & 0.283 & 0.595 & & 16.928 & 25.342 & & & \\
\hline \multirow[t]{3}{*}{$\begin{array}{l}\frac{\text { TRAIT vs NO-TRAIT in Vote Treat. }}{\text { coefficient (TRAIT + Vote }} \text { TRAIT) } \\
\text { pvalue (TRAIT + Vote* TRAIT) }\end{array}$} & & $\begin{array}{c}-0.006 \\
0.850\end{array}$ & $\begin{array}{l}0.012 \\
0.800\end{array}$ & & $\begin{array}{l}-0.024 \\
0.528\end{array}$ & $\begin{array}{l}0.013 \\
0.823\end{array}$ & & $\begin{array}{c}-2.048 \\
0.556\end{array}$ & $\begin{array}{l}-5.358 \\
0.519\end{array}$ & & & \\
\hline & (1) & (2) & (3) & (4) & (5) & (6) & (7) & (8) & (9) & (10) & (11) & (12) \\
\hline & \multicolumn{12}{|c|}{ Panel B: Endline Results (2015) } \\
\hline \multirow{2}{*}{$\begin{array}{l}\text { Dependent Variable } \rightarrow \\
\text { TRAIT (at Baseline) } \rightarrow\end{array}$} & \multicolumn{3}{|c|}{$\begin{array}{l}=1 \text { if received a loan in } \\
\text { the past year from BRAC } \\
\text { group }\end{array}$} & \multicolumn{3}{|c|}{$\begin{array}{l}\text { \# loans received in the } \\
\text { past year from BRAC } \\
\text { group }\end{array}$} & \multicolumn{3}{|c|}{$\begin{array}{l}\text { Amount borrowed in the } \\
\text { past year from BRAC group }\end{array}$} & \multicolumn{3}{|c|}{$\begin{array}{l}\text { Amount ever saved in } \\
\text { BRAC group }\end{array}$} \\
\hline & - & Poor & $\begin{array}{c}\text { Has no } \\
\text { loan }\end{array}$ & - & Poor & $\begin{array}{c}\text { Has no } \\
\text { loan }\end{array}$ & - & Poor & $\begin{array}{c}\text { Has no } \\
\text { loan }\end{array}$ & - & Poor & $\begin{array}{l}\text { Has no } \\
\text { loan }\end{array}$ \\
\hline Vote & $\begin{array}{l}-0.040 \\
(0.050)\end{array}$ & $\begin{array}{l}-0.094^{*} \\
(0.051)\end{array}$ & $\begin{array}{c}-0.198^{* *} \\
(0.098)\end{array}$ & $\begin{array}{l}-0.079 \\
(0.104)\end{array}$ & $\begin{array}{l}-0.167^{*} \\
(0.100)\end{array}$ & $\begin{array}{c}-0.497^{* *} \\
(0.209)\end{array}$ & $\begin{array}{c}-4.742 \\
(9.434)\end{array}$ & $\begin{array}{c}-11.528 \\
(10.270)\end{array}$ & $\begin{array}{c}-51.647^{* *} \\
(20.324)\end{array}$ & $\begin{array}{c}12.216 \\
(19.561)\end{array}$ & $\begin{array}{c}13.898 \\
(21.107)\end{array}$ & $\begin{array}{c}-3.750 \\
(27.845)\end{array}$ \\
\hline TRAIT & & $\begin{array}{c}-0.097^{*} \\
(0.051)\end{array}$ & $\begin{array}{c}-0.205^{* * *} \\
(0.070)\end{array}$ & & $\begin{array}{c}-0.223^{* *} \\
(0.092)\end{array}$ & $\begin{array}{c}-0.507^{* * *} \\
(0.164)\end{array}$ & & $\begin{array}{c}-24.295^{* * *} \\
(7.791)\end{array}$ & $\begin{array}{c}-52.784^{* * *} \\
(17.979)\end{array}$ & & $\begin{array}{c}-10.981 \\
(13.873)\end{array}$ & $\begin{array}{l}-33.985 \\
(21.435)\end{array}$ \\
\hline Vote $^{*}$ TRAIT & & $\begin{array}{l}0.175^{* *} \\
(0.069)\end{array}$ & $\begin{array}{c}0.180^{* *} \\
(0.087)\end{array}$ & & $\begin{array}{c}0.347^{* *} \\
(0.147)\end{array}$ & $\begin{array}{l}0.481^{* *} \\
(0.204)\end{array}$ & & $\begin{array}{l}27.905^{* *} \\
(11.770)\end{array}$ & $\begin{array}{c}55.956^{* * *} \\
(19.298)\end{array}$ & & $\begin{array}{c}6.701 \\
(24.956)\end{array}$ & $\begin{array}{c}36.401 \\
(26.611)\end{array}$ \\
\hline Observations (Members) & 731 & 714 & 639 & 730 & 713 & 638 & 679 & 664 & 594 & 642 & 628 & 560 \\
\hline R-squared & 0.126 & 0.132 & 0.150 & 0.137 & 0.138 & 0.161 & 0.120 & 0.126 & 0.158 & 0.224 & 0.224 & 0.262 \\
\hline Mean dep var in Discussion & 0.394 & 0.394 & 0.394 & 0.713 & 0.713 & 0.713 & 50.483 & 50.483 & 50.483 & 115.219 & 115.219 & 115.219 \\
\hline Mean dep var in Disc. \& NO-TRAIT & & 0.423 & 0.522 & & 0.766 & 1.087 & & 58.521 & 91.860 & & 117.230 & 119.595 \\
\hline$\frac{\text { TRAIT vs NO-TRAIT in Vote Treat. }}{\text { coefficient (TRAIT + Vote }{ }^{\star} \text { TRAIT) }}$ & & 0.078 & -0.025 & & 0.124 & -0.026 & & 3.610 & 3.172 & & -4.280 & 2.417 \\
\hline pvalue (TRAIT + Vote* TRAIT) & & 0.099 & 0.645 & & 0.287 & 0.840 & & 0.687 & 0.716 & & 0.840 & 0.867 \\
\hline
\end{tabular}

Notes: This table compares loan access, membership and savings across treatments. "Poor" is a dummy equal to 1 if an individual belongs to the bottom $25 \%$ of the group wealth score distribution at Baseline. "Has no loan" is a dummy equal to 1 if an individual had no loans at Baseline. Amount borrowed (in UGX) is the total value of any loans taken in the past year (takes a value of 0 if no loans were received). Amount ever saved in the group is the amount saved since group formation (in UGX). All regressions include branch fixed effects and robust standard errors clustered at the group level. Endline results also include sample weights to account for the fact that across relevant subgroups, different proportions of the Baseline members were interviewed at Endline (see Table A.1 for more details). ${ }^{*} \mathrm{p}<0.1,{ }^{* *} \mathrm{p}<0.05,{ }^{* * *}$ $\mathrm{p}<0.01$. 


\section{TABLE 5: TREATMENT EFFECTS ON MEMBERSHIP}

\begin{tabular}{|c|c|c|c|c|c|c|}
\hline \multirow{4}{*}{$\begin{array}{c}\text { Dependent Variable } \rightarrow \\
\text { TRAIT (at Baseline) } \rightarrow\end{array}$} & (1) & (2) & (3) & (4) & (5) & (6) \\
\hline & \multicolumn{3}{|c|}{ Midline Results (2013) } & \multicolumn{3}{|c|}{ Endline Results (2015) } \\
\hline & \multicolumn{6}{|c|}{$=1$ if stayer (still a group member) } \\
\hline & - & Poor & $\begin{array}{c}\text { Has no } \\
\text { loan }\end{array}$ & - & Poor & $\begin{array}{c}\text { Has no } \\
\text { loan }\end{array}$ \\
\hline Vote & $\begin{array}{l}0.138^{* *} \\
(0.052)\end{array}$ & $\begin{array}{l}0.113^{* *} \\
(0.055)\end{array}$ & $\begin{array}{c}0.069 \\
(0.121)\end{array}$ & $\begin{array}{c}0.061 \\
(0.037)\end{array}$ & $\begin{array}{c}0.037 \\
(0.039)\end{array}$ & $\begin{array}{c}0.098 \\
(0.089)\end{array}$ \\
\hline TRAIT & & $\begin{array}{l}-0.070 * \\
(0.035)\end{array}$ & $\begin{array}{c}-0.206^{* * *} \\
(0.076)\end{array}$ & & $\begin{array}{c}-0.026 \\
(0.033)\end{array}$ & $\begin{array}{c}-0.000 \\
(0.065)\end{array}$ \\
\hline Vote $^{*}$ TRAIT & & $\begin{array}{c}0.073 \\
(0.048)\end{array}$ & $\begin{array}{c}0.094 \\
(0.116)\end{array}$ & & $\begin{array}{l}0.079^{*} \\
(0.046)\end{array}$ & $\begin{array}{c}-0.032 \\
(0.086)\end{array}$ \\
\hline Observations (Members) & 1,450 & 1,416 & 1,281 & 1,450 & 1,416 & 1,281 \\
\hline R-squared & 0.228 & 0.225 & 0.236 & 0.165 & 0.173 & 0.171 \\
\hline Mean dep var in Discussion & 0.408 & 0.408 & 0.408 & 0.208 & 0.208 & 0.208 \\
\hline $\begin{array}{l}\text { Mean dep var in Discussion \& NO-TRAIT } \\
\text { TRAIT vs NO-TRAIT in Vote Treatment }\end{array}$ & & 0.430 & 0.553 & & 0.217 & 0.224 \\
\hline coefficient $\left(\right.$ TRAIT + Vote $^{*}$ TRAIT) & & 0.004 & -0.111 & & 0.053 & -0.032 \\
\hline pvalue (TRAIT + Vote* TRAIT) & & 0.909 & 0.169 & & 0.127 & 0.571 \\
\hline
\end{tabular}

Notes: This table compares membership rates across treatments. Dependent variable is a dummy for whether the respondent is still a member of the group at Midline/Endline. "Poor" is a dummy equal to 1 if an individual belongs to the bottom $25 \%$ of the group wealth score distribution at Baseline. "Has no loan" is a dummy equal to 1 if an individual had no loans at Baseline. All regressions include branch fixed effects and robust standard errors clustered at the group level. Endline results also include sample weights to account for the fact that across relevant sub-groups, different proportions of the Baseline members were interviewed at Endline (see Table A.1 for more details). ${ }^{*} \mathrm{p}<0.1,{ }^{* *} \mathrm{p}<0.05,{ }^{* * *} \mathrm{p}<0.01$. 


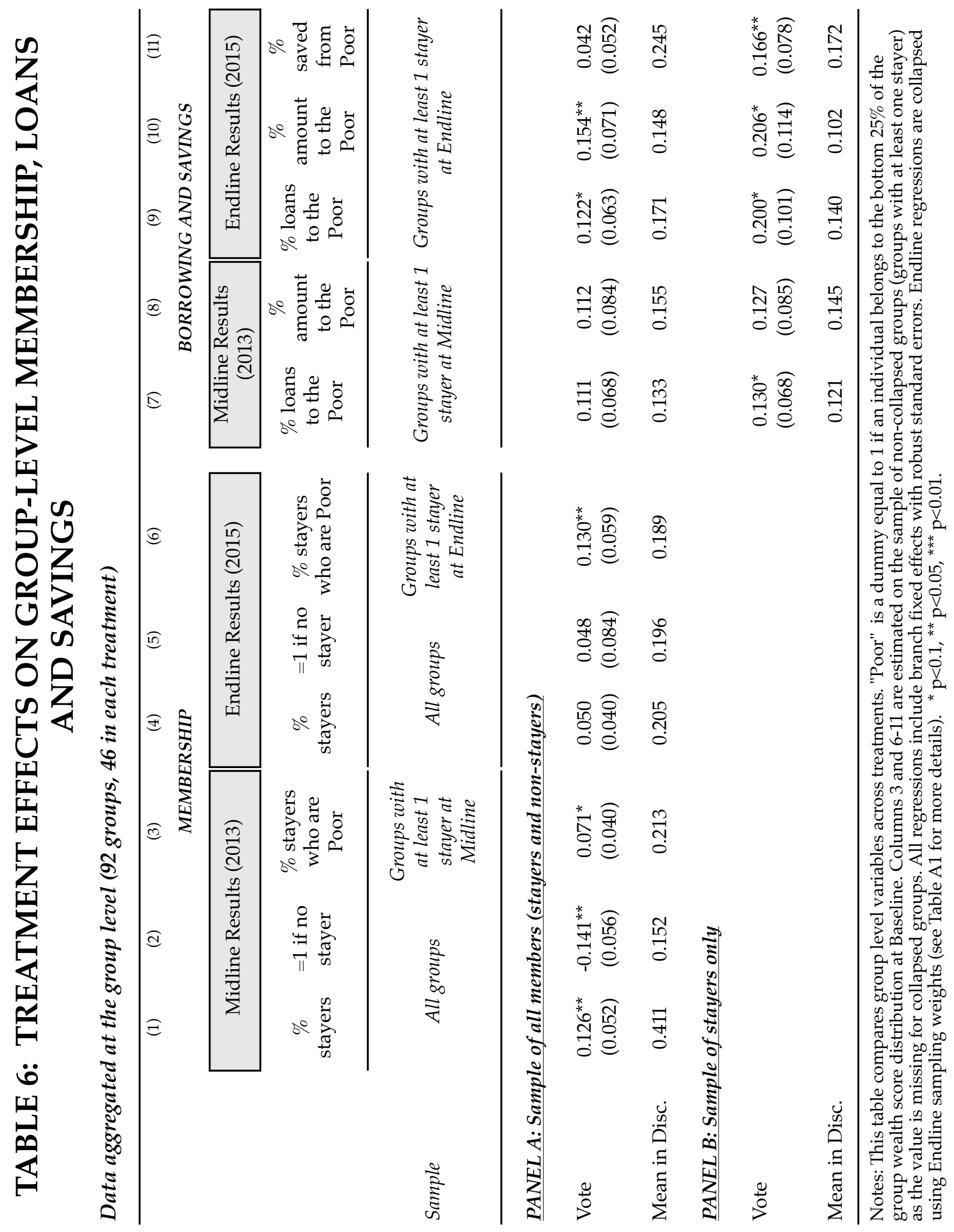









\section{TABLE A.1: SAMPLING FOR ENDLINE SURVEY}

\begin{tabular}{cccccc} 
Status & Treatment & $\begin{array}{c}\text { Share sampled for } \\
\text { Endline Survey } \\
\text { (among those } \\
\text { surveyed at } \\
\text { Baseline) }\end{array}$ & $\begin{array}{c}\text { Response rate } \\
\text { at Endline } \\
\text { among those } \\
\text { sampled) }\end{array}$ & $\begin{array}{c}\text { Share } \\
\text { interviewed at } \\
\text { Endline=Share } \\
\text { sampled } \\
\text { Response rate }\end{array}$ & $\begin{array}{c}\text { Endline Weight } \\
=1 / \text { Share } \\
\text { interviewed at } \\
\text { Endline }\end{array}$ \\
\hline Stayers & Discussion & $100 \%$ & $84 \%$ & $84 \%$ & 1.19 \\
Stayers & Vote & $100 \%$ & $78 \%$ & $78 \%$ & 1.28 \\
Leavers & Discussion & $40 \%$ & $83 \%$ & $33 \%$ & 3.01 \\
Leavers & Vote & $40 \%$ & $92 \%$ & $37 \%$ & 2.72 \\
\hline
\end{tabular}

Note: We sampled all stayers but only about $40 \%$ of the leavers. Among those sampled to be part of the Endline Survey, a number of respondent were either not found or did not agree to participate in the survey. As a consequence, response rate is not $100 \%$ but is balanced across treatments. The last column indicates the sampling weights given to each group when performing analysis using Endline results.

\section{TABLE A.2: PAIRWISE CORRELATIONS AT BASELINE}

\begin{tabular}{|c|c|c|}
\hline & $\begin{array}{c}(1) \\
\text { Wealth score } \\
(0 \text { to } 100)\end{array}$ & $\begin{array}{l}\text { (2) } \\
\text { Has completed } \\
\text { primary school }\end{array}$ \\
\hline Total amount saved & $0.085^{\star * *}$ & $0.095^{* * *}$ \\
\hline Total amount borrowed & 0.012 & -0.031 \\
\hline Wealth score (0 to 100$)$ & 1 & $0.328^{* * *}$ \\
\hline Value of assets owned & $0.064^{* *}$ & 0.021 \\
\hline Has ever enrolled in school & $0.360^{* * *}$ & $0.332^{* * *}$ \\
\hline Has completed primary school & $0.328^{* * *}$ & 1 \\
\hline Has participated in business training & 0.042 & $0.094^{* * *}$ \\
\hline Has received advice on earning activies in the past year & -0.037 & $0.094^{* * *}$ \\
\hline Has worked / studied outside village for at least 1 year & $0.203^{* * *}$ & $0.216^{* * *}$ \\
\hline Does not belong to majority tribe & $0.200^{* * *}$ & -0.018 \\
\hline Share of group members who are close friends & 0.035 & $0.071^{* * *}$ \\
\hline
\end{tabular}

Notes: This table shows parwise correlations between the wealth score/ completion of primary school and other Baseline variables. See notes of Table 1 for more details on each variable. ${ }^{*} p<0.1,{ }^{* *} p<0.05,{ }^{* * *} p<0.01$. 


\section{TABLE A.3: DIFFERENCES BETWEEN COMMITTEE MEMBERS ACROSS TREATMENTS, BY POSITION}

\begin{tabular}{|c|c|c|c|c|c|c|c|c|}
\hline \multirow[b]{3}{*}{ Dependent variable $\rightarrow$} & $(1)$ & $(2)$ & (3) & $(4)$ & $(5)$ & (6) & $(7)$ & $(8)$ \\
\hline & \multicolumn{2}{|c|}{ Wealth } & \multicolumn{3}{|c|}{ Education and Training } & \multicolumn{3}{|c|}{ Social connections and background } \\
\hline & $\begin{array}{l}\text { Wealth } \\
\text { score } \\
\text { (0 to } 100)\end{array}$ & $\begin{array}{c}\text { Value of } \\
\text { assets } \\
\text { owned }\end{array}$ & $\begin{array}{c}\text { Has } \\
\text { completed } \\
\text { primary } \\
\text { school }\end{array}$ & $\begin{array}{l}\text { Has ever } \\
\text { particip- } \\
\text { ated in } \\
\text { business } \\
\text { training }\end{array}$ & $\begin{array}{c}\text { Has } \\
\text { received } \\
\text { advice on } \\
\text { earning } \\
\text { activies in } \\
\text { the past } \\
\text { year }\end{array}$ & $\begin{array}{c}\text { Has } \\
\text { worked/ } \\
\text { studied } \\
\text { outside } \\
\text { village for } \\
\text { at least } 1 \\
\text { year }\end{array}$ & $\begin{array}{l}\text { Does not } \\
\text { belong to } \\
\text { majority } \\
\text { tribe }\end{array}$ & $\begin{array}{l}\text { Share of } \\
\text { group } \\
\text { members } \\
\text { who are } \\
\text { close } \\
\text { friends }\end{array}$ \\
\hline \multicolumn{9}{|c|}{ SAMPLE $=$ CHAIRPERSON $(\mathrm{N}=92 ; 1$ position per group $)$} \\
\hline Vote & $\begin{array}{l}-8.442^{*} \\
(4.486)\end{array}$ & $\begin{array}{l}1.141 \\
(2.304)\end{array}$ & $\begin{array}{l}-0.065 \\
(0.123)\end{array}$ & $\begin{array}{c}-0.064 \\
(0.126)\end{array}$ & $\begin{array}{c}-0.238^{\star *} \\
(0.110)\end{array}$ & $\begin{array}{l}-0.161 \\
(0.114)\end{array}$ & $\begin{array}{c}-0.136 \\
(0.090)\end{array}$ & $\begin{array}{l}-0.003 \\
(0.025)\end{array}$ \\
\hline Mean Dep Var in Discussion & 27.961 & 2.962 & 0.343 & 0.303 & 0.353 & 0.343 & 0.514 & 0.136 \\
\hline \multicolumn{9}{|c|}{ SAMPLE $=$ KEY HOLDERS $(\mathrm{N}=92 \times 2 ; 2$ positions per group $)$} \\
\hline Vote & $\begin{array}{c}-6.180^{\star * *} \\
(2.294)\end{array}$ & $\begin{array}{l}-1.353^{*} \\
(0.713)\end{array}$ & $\begin{array}{c}-0.031 \\
(0.063)\end{array}$ & $\begin{array}{l}-0.105^{\star} \\
(0.062)\end{array}$ & $\begin{array}{c}-0.168^{* *} \\
(0.065)\end{array}$ & $\begin{array}{l}-0.087 \\
(0.057)\end{array}$ & $\begin{array}{c}-0.001 \\
(0.049)\end{array}$ & $\begin{array}{c}0.001 \\
(0.014)\end{array}$ \\
\hline Mean Dep Var in Discussion & 33.246 & 3.323 & 0.440 & 0.328 & 0.377 & 0.365 & 0.532 & 0.135 \\
\hline \multicolumn{9}{|c|}{ SAMPLE $=$ SECRETARY $(\mathrm{N}=92 ; 1$ position per group $)$} \\
\hline Vote & $\begin{array}{c}0.390 \\
(4.356)\end{array}$ & $\begin{array}{l}-2.978^{*} \\
(1.615)\end{array}$ & $\begin{array}{c}0.068 \\
(0.125)\end{array}$ & $\begin{array}{c}0.030 \\
(0.124)\end{array}$ & $\begin{array}{l}-0.116 \\
(0.111)\end{array}$ & $\begin{array}{c}0.011 \\
(0.116)\end{array}$ & $\begin{array}{c}0.024 \\
(0.104)\end{array}$ & $\begin{array}{c}0.022 \\
(0.038)\end{array}$ \\
\hline Mean Dep Var in Discussion & 29.931 & 4.718 & 0.483 & 0.300 & 0.321 & 0.333 & 0.533 & 0.134 \\
\hline \multicolumn{9}{|c|}{ SAMPLE $=$ TREASURER $(\mathrm{N}=92 ; 1$ position per group $)$} \\
\hline Vote & $\begin{array}{l}-3.178 \\
(4.900)\end{array}$ & $\begin{array}{c}-1.428^{*} \\
(0.728)\end{array}$ & $\begin{array}{c}0.122 \\
(0.132)\end{array}$ & $\begin{array}{l}-0.171 \\
(0.137)\end{array}$ & $\begin{array}{c}0.015 \\
(0.139)\end{array}$ & $\begin{array}{l}-0.188 \\
(0.133)\end{array}$ & $\begin{array}{c}0.024 \\
(0.085)\end{array}$ & $\begin{array}{c}0.014 \\
(0.036)\end{array}$ \\
\hline Mean Dep Var in Discussion & 43.768 & 2.403 & 0.720 & 0.500 & 0.360 & 0.440 & 0.600 & 0.156 \\
\hline
\end{tabular}

Notes: This table compares committee members' characteristics across treatments, for each CM position separately. The sample is restricted to committee members of a given position. See notes of Table 1 for more details on each variable. Branch fixed effects are included in all regressions. Robust standard errors clustered at the group level are presented in brackets. ${ }^{*} \mathrm{p}<0.1,{ }^{* *} \mathrm{p}<0.05,{ }^{* * *} \mathrm{p}<0.01$. 


\section{TABLE A.4: PREDICTORS OF BECOMING A COMMITTEE MEMBER, BY TREATMENT}

\begin{tabular}{|c|c|c|c|c|}
\hline \multirow{3}{*}{$\begin{array}{l}\text { Dependent Variable } \rightarrow \\
\text { Wealth score }\end{array}$} & (1) & (2) & (3) & (4) \\
\hline & \multicolumn{4}{|c|}{$\begin{array}{c}=1 \text { if member becomes committee member, } \\
\text { and } 0 \text { otherwise }\end{array}$} \\
\hline & $\begin{array}{c}0.001 \\
(0.001)\end{array}$ & $\begin{array}{l}0.001 \\
(0.001)\end{array}$ & $\begin{array}{c}0.001 \\
(0.001)\end{array}$ & $\begin{array}{c}0.001 \\
(0.001)\end{array}$ \\
\hline Assets value & $\begin{array}{l}-0.001 \\
(0.002)\end{array}$ & $\begin{array}{l}-0.000 \\
(0.002)\end{array}$ & $\begin{array}{c}0.003 \\
(0.003)\end{array}$ & $\begin{array}{l}0.005 \\
(0.004)\end{array}$ \\
\hline Has completed primary school & $\begin{array}{c}0.157^{* * *} \\
(0.036)\end{array}$ & $\begin{array}{c}0.146^{* * *} \\
(0.034)\end{array}$ & $\begin{array}{c}0.226^{* * *} \\
(0.056)\end{array}$ & $\begin{array}{c}0.189^{* * *} \\
(0.057)\end{array}$ \\
\hline Has participated in business training & $\begin{array}{l}0.043 \\
(0.035)\end{array}$ & $\begin{array}{l}-0.003 \\
(0.036)\end{array}$ & $\begin{array}{l}0.018 \\
(0.044)\end{array}$ & $\begin{array}{l}0.004 \\
(0.045)\end{array}$ \\
\hline Advice on earning activies in past year & & $\begin{array}{c}-0.053^{* *} \\
(0.023)\end{array}$ & & $\begin{array}{l}-0.010 \\
(0.029)\end{array}$ \\
\hline Worked or studied outside village & & $\begin{array}{l}0.033 \\
(0.026)\end{array}$ & & $\begin{array}{l}0.074^{* *} \\
(0.028)\end{array}$ \\
\hline Does not belong to majority tribe & & $\begin{array}{l}-0.008 \\
(0.037)\end{array}$ & & $\begin{array}{l}0.056 \\
(0.041)\end{array}$ \\
\hline Share of close friends in group & & $\begin{array}{c}1.064^{* * *} \\
(0.140)\end{array}$ & & $\begin{array}{c}0.858^{* * *} \\
(0.199)\end{array}$ \\
\hline Vote & & & $\begin{array}{c}0.038 \\
(0.039)\end{array}$ & $\begin{array}{l}0.094^{*} \\
(0.052)\end{array}$ \\
\hline Vote ${ }^{*}$ Wealth score & & & $\begin{array}{l}-0.000 \\
(0.001)\end{array}$ & $\begin{array}{c}0.001 \\
(0.001)\end{array}$ \\
\hline Vote * Assets value & & & $\begin{array}{c}-0.007^{\star *} \\
(0.003)\end{array}$ & $\begin{array}{c}-0.011^{* * *} \\
(0.004)\end{array}$ \\
\hline Vote ${ }^{*}$ Business training & & & $\begin{array}{l}-0.128^{*} \\
(0.071)\end{array}$ & $\begin{array}{c}-0.088 \\
(0.069)\end{array}$ \\
\hline Vote ${ }^{*}$ Has completed primary school & & & $\begin{array}{c}0.057 \\
(0.055)\end{array}$ & $\begin{array}{c}-0.016 \\
(0.061)\end{array}$ \\
\hline Vote ${ }^{*}$ Advice on earning activies & & & & $\begin{array}{c}-0.088^{* *} \\
(0.042)\end{array}$ \\
\hline Vote * Worked or studied outside village & & & & $\begin{array}{c}-0.064 \\
(0.041)\end{array}$ \\
\hline Vote ${ }^{*}$ Does not belong to majority tribe & & & & $\begin{array}{c}-0.117^{* * *} \\
(0.041)\end{array}$ \\
\hline Vote * Share of close friends & & & & $\begin{array}{c}0.447 \\
(0.269)\end{array}$ \\
\hline Observations (Members) & 1,352 & 1,254 & 1,352 & 1,254 \\
\hline R-squared & 0.053 & 0.120 & 0.061 & 0.133 \\
\hline
\end{tabular}

Notes: The dependent variable is a dummy that equals 1 if a group member becomes a committee member. See notes of Table 1 for more details on each variable. Robust standard errors clustered at the group level are presented in brackets. All regressions include branch fixed effects. ${ }^{*} \mathrm{p}<0.1,{ }^{* *}$ $\mathrm{p}<0.05,{ }^{* * *} \mathrm{p}<0.01$ 


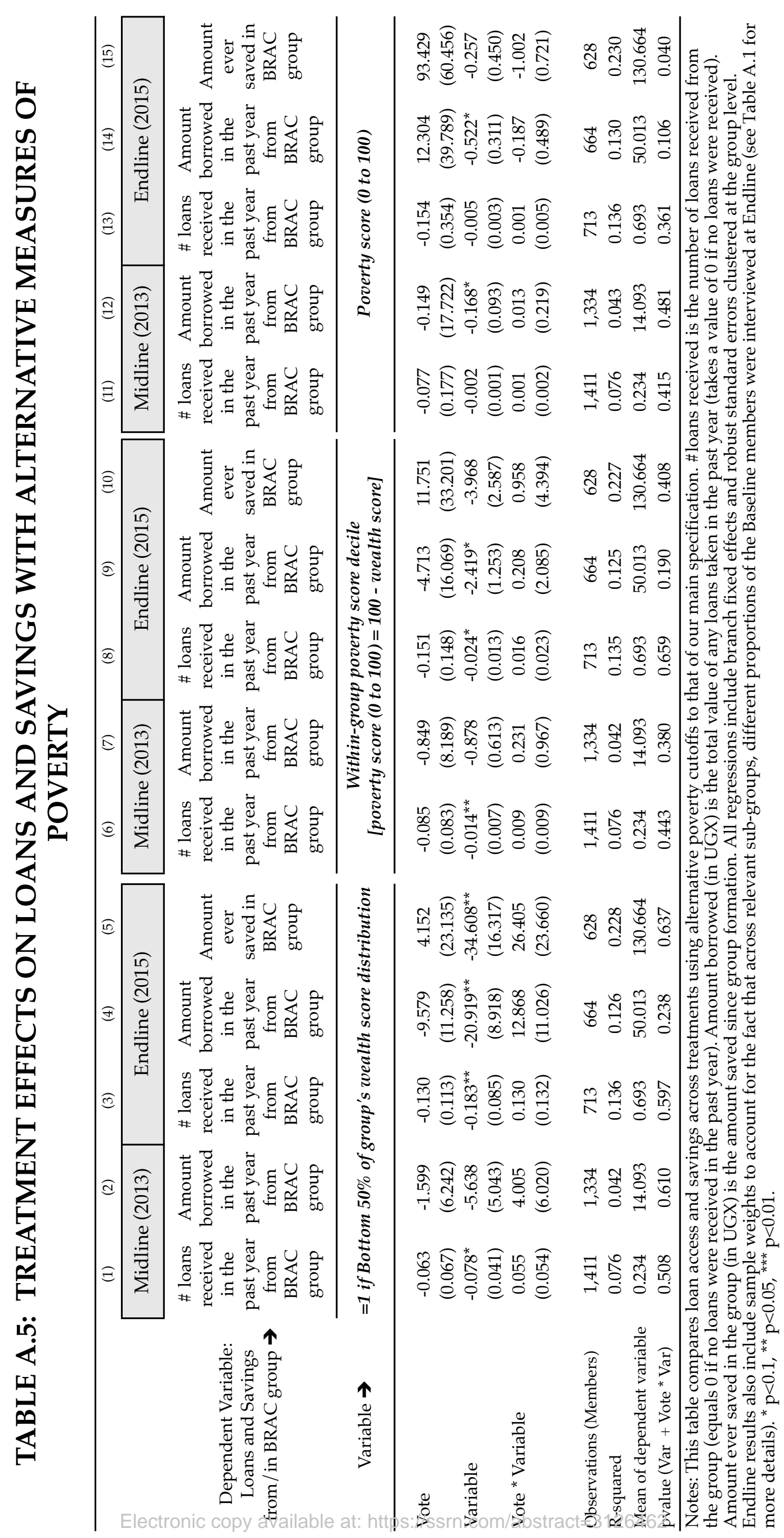




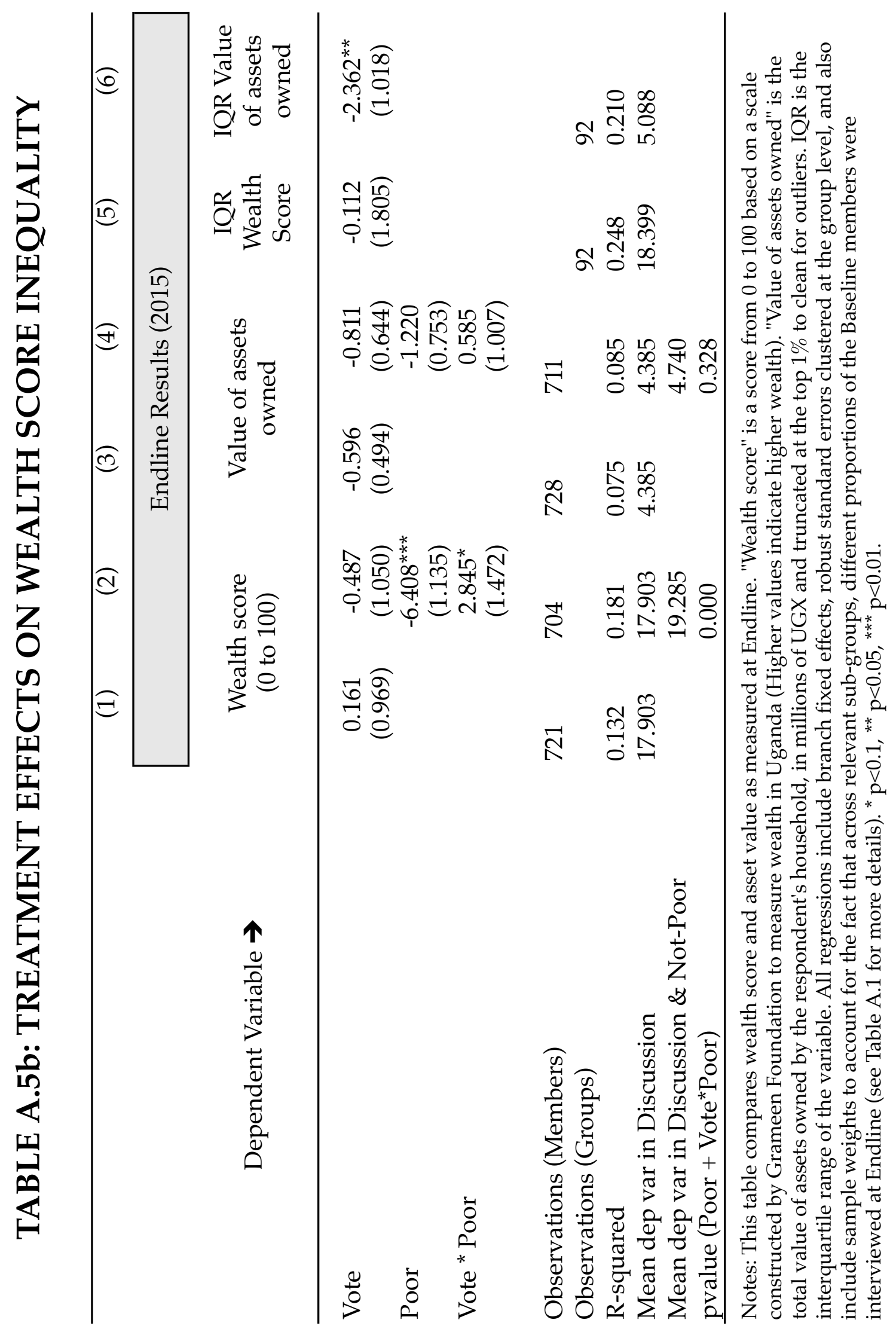




\section{TABLE A.6: TREATMENT EFFECTS ON LOANS AND SAVINGS FOR "STAYERS"}

\begin{tabular}{|c|c|c|c|c|c|c|c|c|c|}
\hline \multirow{4}{*}{$\begin{array}{l}\text { Dependent Variable } \rightarrow \\
\text { TRAIT (at Baseline) } \rightarrow\end{array}$} & (1) & (2) & (3) & (4) & (5) & (6) & (7) & (8) & (9) \\
\hline & \multicolumn{9}{|c|}{ Panel A: Midline Results (2013) } \\
\hline & \multicolumn{3}{|c|}{$\begin{array}{c}=1 \text { if received a loan in the } \\
\text { past year from BRAC } \\
\text { group }\end{array}$} & \multicolumn{3}{|c|}{$\begin{array}{c}\text { \# loans received in the } \\
\text { past year from BRAC } \\
\text { group }\end{array}$} & \multicolumn{3}{|c|}{$\begin{array}{l}\text { Amount borrowed in the past } \\
\text { year from BRAC group }\end{array}$} \\
\hline & - & Poor & $\begin{array}{c}\text { Has no } \\
\text { loan }\end{array}$ & - & Poor & $\begin{array}{l}\text { Has no } \\
\text { loan }\end{array}$ & - & Poor & $\begin{array}{l}\text { Has no } \\
\text { loan }\end{array}$ \\
\hline Vote & $\begin{array}{l}-0.100 \\
(0.069)\end{array}$ & $\begin{array}{l}-0.102 \\
(0.067)\end{array}$ & $\begin{array}{c}-0.369^{* *} \\
(0.148)\end{array}$ & $\begin{array}{l}-0.208^{*} \\
(0.120)\end{array}$ & $\begin{array}{c}-0.255^{\star *} \\
(0.116)\end{array}$ & $\begin{array}{c}-0.731^{\star * *} \\
(0.257)\end{array}$ & $\begin{array}{l}-12.252 \\
(10.405)\end{array}$ & $\begin{array}{l}-15.733 \\
(11.642)\end{array}$ & $\begin{array}{l}-21.651 \\
(20.432)\end{array}$ \\
\hline TRAIT & & $\begin{array}{l}-0.038 \\
(0.055)\end{array}$ & $\begin{array}{l}-0.188 \\
(0.121)\end{array}$ & & $\begin{array}{c}-0.218^{* *} \\
(0.092)\end{array}$ & $\begin{array}{c}-0.458^{\star *} \\
(0.229)\end{array}$ & & $\begin{array}{c}-17.806^{* *} \\
(8.604)\end{array}$ & $\begin{array}{l}-12.188 \\
(18.522)\end{array}$ \\
\hline Vote ${ }^{*}$ TRAIT & & $\begin{array}{l}0.026 \\
(0.074)\end{array}$ & $\begin{array}{l}0.286^{* *} \\
(0.140)\end{array}$ & & $\begin{array}{l}0.159 \\
(0.116)\end{array}$ & $\begin{array}{l}0.555^{* *} \\
(0.236)\end{array}$ & & $\begin{array}{c}12.122 \\
(10.402)\end{array}$ & $\begin{array}{l}11.370 \\
(20.578)\end{array}$ \\
\hline Observations (Stayers at Midline) & 680 & 663 & 583 & 696 & 678 & 599 & 616 & 601 & 531 \\
\hline R-squared & 0.144 & 0.141 & 0.167 & 0.141 & 0.146 & 0.179 & 0.151 & 0.159 & 0.171 \\
\hline Mean dep var in Discussion & 0.427 & 0.427 & 0.427 & 0.614 & 0.614 & 0.614 & 38.554 & 38.554 & 38.554 \\
\hline $\begin{array}{l}\text { Mean dep var in Disc. \& NO-TRAIT } \\
\text { TRAIT vs NO-TRAIT in Vote Treatment }\end{array}$ & & 0.430 & 0.644 & & 0.662 & 1.087 & & 43.661 & 52.857 \\
\hline coefficient (TRAIT + Vote* TRAIT) & & -0.012 & 0.098 & & -0.060 & 0.097 & & -5.684 & -0.818 \\
\hline pvalue (TRAIT + Vote* TRAIT) & & 0.804 & 0.118 & & 0.318 & 0.323 & & 0.329 & 0.947 \\
\hline
\end{tabular}

(1)

(2)

(3)

(4)

(5) (6)

(7)

(8)

(9)

(10)

(11)

(12)

Panel B: Endline Results (2015)

Dependent Variable

$=1$ if received a loan in the past year from BRAC group

- $\quad$ Poor $\begin{gathered}\text { Has no } \\ \text { loan }\end{gathered}$

TRAIT (at Baseline)

Vote

(2)

Vote

TRAIT

Vote * TRAIT

Observations (Stayers at Endline)

R-squared

Mean dep var in Discussion

Mean dep var in Disc. \& NO-TRAIT

TRAIT vs NO-TRAIT in Vote Treatment coefficient (TRAIT + Vote* TRAIT)

pvalue (TRAIT + Vote* TRAIT)

$\begin{array}{ccc}-0.063 & -0.110^{* *} & -0.204^{*} \\ (0.052) & (0.053) & (0.121) \\ & -0.068 & -0.175^{* *} \\ & (0.061) & (0.083) \\ & 0.149^{*} & 0.146 \\ & (0.083) & (0.108)\end{array}$

\# loans received in the past year from BRAC group

- Poor $\begin{gathered}\text { Has no } \\ \text { loan }\end{gathered}$

Amount borrowed in the past year from BRAC group

\begin{tabular}{ccc}
\hline- & Poor & $\begin{array}{c}\text { Has no } \\
\text { loan }\end{array}$ \\
\hline-5.783 & -11.029 & $-40.035^{*}$ \\
$(6.917)$ & $(7.796)$ & $(20.716)$ \\
& $-13.827^{*}$ & $-33.971^{*}$ \\
& $(7.510)$ & $(19.241)$ \\
& $23.112^{*}$ & $38.292^{*}$ \\
& $(11.799)$ & $(20.022)$
\end{tabular}

Amount ever saved in BRAC group

\begin{tabular}{ccc}
\hline- & Poor & $\begin{array}{c}\text { Has no } \\
\text { loan }\end{array}$ \\
\hline-5.747 & -8.413 & -31.782 \\
$(15.130)$ & $(15.035)$ & $(27.844)$ \\
& -6.259 & -19.511 \\
& $(13.720)$ & $(24.479)$ \\
& 21.254 & 38.068 \\
& $(24.404)$ & $(29.683)$
\end{tabular}

$\begin{array}{cccccc}471 & 457 & 422 & 470 & 456 & 421 \\ 0.096 & 0.100 & 0.114 & 0.115 & 0.103 & 0.124 \\ 0.277 & 0.277 & 0.277 & 0.462 & 0.462 & 0.462 \\ & 0.294 & 0.414 & & 0.469 & 0.828 \\ & & & & & \\ & 0.081 & -0.030 & & 0.184 & 0.053 \\ & 0.150 & 0.651 & & 0.176 & 0.524\end{array}$

$\begin{array}{ccc}454 & 440 & 407 \\ 0.082 & 0.073 & 0.110 \\ 28.314 & 28.314 & 28.314 \\ & 30.433 & 57.037 \\ & & \\ & 9.285 & 4.322 \\ & 0.316 & 0.419\end{array}$

$\begin{array}{ccc}406 & 395 & 365 \\ 0.137 & 0.140 & 0.204 \\ 85.204 & 85.204 & 85.204 \\ & 86.232 & 108.333 \\ & 14.996 & 18.557 \\ & 0.467 & 0.269\end{array}$

( 1 if an indivle compares loan access, membership and savings across treatments. The sample is restricted to "stayers" at Endline. "Poor" is a dummy equal loans at Baseline. \#loans received is the number of loans received from the group (equals 0 if no loans were received in the past year). Amount borrowed (in UGX) is the total value of any loans taken in the past year (takes a value of 0 if no loans were received). Amount ever saved in the group (in UGX) is the amount saved since group formation. All regressions include branch fixed effects and robust standard errors clustered at the group level. Endline results also include sample weights to account for the fact that across relevant sub-groups, different proportions of the Baseline members were interviewed at Endline (see Table A.1 for more details). ${ }^{*} \mathrm{p}<0.1,{ }^{* *} \mathrm{p}<0.05,{ }^{* * *} \mathrm{p}<0.01$. 


\section{TABLE A.7: TREATMENT EFFECTS ON LOANS AND SAVINGS FOR " REGULAR (NON- COMMITTEE) MEMBERS"}

\begin{tabular}{|c|c|c|c|c|c|c|c|c|c|}
\hline \multirow{4}{*}{$\begin{array}{l}\text { Dependent Variable } \rightarrow \\
\text { TRAIT (at Baseline) } \rightarrow\end{array}$} & (1) & (2) & (3) & (4) & (5) & (6) & (7) & (8) & (9) \\
\hline & \multicolumn{9}{|c|}{ Panel A: Midline Results (2013) } \\
\hline & \multicolumn{3}{|c|}{$\begin{array}{l}=1 \text { if received a loan in } \\
\text { the past year from BRAC } \\
\text { group }\end{array}$} & \multicolumn{3}{|c|}{$\begin{array}{l}\text { \# loans received in the } \\
\text { past year from BRAC } \\
\text { group }\end{array}$} & \multicolumn{3}{|c|}{$\begin{array}{l}\text { Amount borrowed in the } \\
\text { past year from BRAC group }\end{array}$} \\
\hline & - & Poor & $\begin{array}{c}\text { Has no } \\
\text { loan }\end{array}$ & - & Poor & $\begin{array}{l}\text { Has no } \\
\text { loan }\end{array}$ & - & Poor & $\begin{array}{c}\text { Has no } \\
\text { loan }\end{array}$ \\
\hline Vote & $\begin{array}{c}0.001 \\
(0.036)\end{array}$ & $\begin{array}{l}-0.008 \\
(0.038)\end{array}$ & $\begin{array}{l}-0.129 \\
(0.117)\end{array}$ & $\begin{array}{l}-0.038 \\
(0.057)\end{array}$ & $\begin{array}{l}-0.069 \\
(0.067)\end{array}$ & $\begin{array}{l}-0.328^{*} \\
(0.189)\end{array}$ & $\begin{array}{c}0.287 \\
(4.625)\end{array}$ & $\begin{array}{l}-1.484 \\
(6.059)\end{array}$ & $\begin{array}{l}-10.529 \\
(12.548)\end{array}$ \\
\hline TRAIT & & $\begin{array}{l}-0.034 \\
(0.022)\end{array}$ & $\begin{array}{l}-0.128 \\
(0.096)\end{array}$ & & $\begin{array}{c}-0.124^{* *} \\
(0.054)\end{array}$ & $\begin{array}{l}-0.255 \\
(0.178)\end{array}$ & & $\begin{array}{c}-9.768^{* *} \\
(4.855)\end{array}$ & $\begin{array}{l}-14.196 \\
(10.104)\end{array}$ \\
\hline Vote $^{*}$ TRAIT & & $\begin{array}{c}0.042 \\
(0.041)\end{array}$ & $\begin{array}{c}0.144 \\
(0.111)\end{array}$ & & $\begin{array}{l}0.111^{*} \\
(0.061)\end{array}$ & $\begin{array}{l}0.321^{*} \\
(0.179)\end{array}$ & & $\begin{array}{c}5.312 \\
(5.873)\end{array}$ & $\begin{array}{c}12.434 \\
(11.790)\end{array}$ \\
\hline Observations (Regular members only' & 1,116 & 1,093 & 987 & 1,127 & 1,104 & 998 & 1,076 & 1,055 & 953 \\
\hline R-squared & 0.073 & 0.070 & 0.072 & 0.074 & 0.074 & 0.083 & 0.037 & 0.042 & 0.045 \\
\hline Mean dep var in Discussion & 0.138 & 0.138 & 0.138 & 0.191 & 0.191 & 0.191 & 10.640 & 10.640 & 10.640 \\
\hline $\begin{array}{l}\text { Mean dep var in Disc. \& NO-TRAIT } \\
\text { Treatment }\end{array}$ & & 0.144 & 0.262 & & 0.223 & 0.426 & & 13.407 & 21.786 \\
\hline coefficient (TRAIT + Vote* TRAIT) & & 0.009 & 0.015 & & -0.013 & 0.066 & & -4.457 & -1.762 \\
\hline pvalue (TRAIT + Vote* TRAIT) & & 0.797 & 0.791 & & 0.708 & 0.113 & & 0.162 & 0.803 \\
\hline
\end{tabular}

\begin{tabular}{|c|c|c|c|c|c|c|c|c|c|c|c|c|}
\hline \multirow{4}{*}{$\begin{array}{l}\text { Dependent Variable } \rightarrow \\
\text { TRAIT (at Baseline) } \rightarrow\end{array}$} & (1) & (2) & (3) & (4) & (5) & (6) & (7) & (8) & (9) & (10) & (11) & (12) \\
\hline & \multicolumn{12}{|c|}{ Panel B: Endline Results (2015) } \\
\hline & \multicolumn{3}{|c|}{$\begin{array}{c}=1 \text { if received a loan in } \\
\text { the past year from BRAC } \\
\text { group }\end{array}$} & \multicolumn{3}{|c|}{$\begin{array}{l}\text { \# loans received in the } \\
\text { past year from BRAC } \\
\text { group }\end{array}$} & \multicolumn{3}{|c|}{$\begin{array}{l}\text { Amount borrowed in the } \\
\text { past year from BRAC group }\end{array}$} & \multicolumn{3}{|c|}{$\begin{array}{l}\text { Amount ever saved in } \\
\text { BRAC group }\end{array}$} \\
\hline & - & Poor & $\begin{array}{l}\text { Has no } \\
\text { loan }\end{array}$ & - & Poor & $\begin{array}{l}\text { Has no } \\
\text { loan }\end{array}$ & - & Poor & $\begin{array}{l}\text { Has no } \\
\text { loan }\end{array}$ & - & Poor & $\begin{array}{l}\text { Has no } \\
\text { loan }\end{array}$ \\
\hline Vote & $\begin{array}{l}-0.072 \\
(0.052)\end{array}$ & $\begin{array}{c}-0.123^{* *} \\
(0.055)\end{array}$ & $\begin{array}{l}-0.224^{*} \\
(0.116)\end{array}$ & $\begin{array}{l}-0.156 \\
(0.104)\end{array}$ & $\begin{array}{c}-0.226^{* *} \\
(0.100)\end{array}$ & $\begin{array}{c}-0.482^{* *} \\
(0.184)\end{array}$ & $\begin{array}{r}-10.042 \\
(9.262)\end{array}$ & $\begin{array}{l}-14.864 \\
(9.810)\end{array}$ & $\begin{array}{l}-61.240^{* * *} \\
(19.735)\end{array}$ & $\begin{array}{c}12.638 \\
(21.824)\end{array}$ & $\begin{array}{c}18.196 \\
(23.812)\end{array}$ & $\begin{array}{c}-4.446 \\
(29.326)\end{array}$ \\
\hline TRAIT & & $\begin{array}{l}-0.081 \\
(0.060)\end{array}$ & $\begin{array}{c}-0.189^{* *} \\
(0.092)\end{array}$ & & $\begin{array}{l}-0.187^{\star} \\
(0.109)\end{array}$ & $\begin{array}{l}-0.337^{\star} \\
(0.172)\end{array}$ & & $\begin{array}{c}-19.905^{* *} \\
(9.203)\end{array}$ & $\begin{array}{c}-40.871^{\star *} \\
(19.588)\end{array}$ & & $\begin{array}{c}-3.709 \\
(16.605)\end{array}$ & $\begin{array}{c}-7.925 \\
(20.330)\end{array}$ \\
\hline Vote ${ }^{*}$ TRAIT & & $\begin{array}{l}0.172^{* *} \\
(0.076)\end{array}$ & $\begin{array}{c}0.183 \\
(0.111)\end{array}$ & & $\begin{array}{l}0.328^{* *} \\
(0.162)\end{array}$ & $\begin{array}{l}0.404^{* *} \\
(0.194)\end{array}$ & & $\begin{array}{l}22.704^{* *} \\
(10.438)\end{array}$ & $\begin{array}{c}61.836^{* * *} \\
(21.285)\end{array}$ & & $\begin{array}{l}-10.554 \\
(28.576)\end{array}$ & $\begin{array}{c}39.981 \\
(29.839)\end{array}$ \\
\hline Observations (Regular members only) & 541 & 531 & 473 & 540 & 530 & 472 & 501 & 491 & 437 & 468 & 461 & 410 \\
\hline R-squared & 0.134 & 0.143 & 0.172 & 0.150 & 0.154 & 0.179 & 0.128 & 0.131 & 0.180 & 0.223 & 0.227 & 0.263 \\
\hline Mean dep var in Discussion & 0.389 & 0.389 & 0.389 & 0.706 & 0.706 & 0.706 & 45.880 & 45.880 & 45.880 & 107.735 & 107.735 & 107.735 \\
\hline Mean dep var in Disc. \& NO-TRAIT & & 0.416 & 0.485 & & 0.755 & 0.909 & & 52.168 & 74.355 & & 107.680 & 89.000 \\
\hline$\frac{\text { TRAIT vs NO-TRAIT in Vote Treatment }}{\text { coefficient (TRAIT + Vote }{ }^{\star} \text { TRAIT) }}$ & & 0.091 & -0.005 & & 0.142 & 0.067 & & 2.799 & 20.965 & & -14.263 & 32.057 \\
\hline pvalue (TRAIT + Vote* TRAIT) & & 0.065 & 0.940 & & 0.267 & 0.556 & & 0.656 & 0.046 & & 0.553 & 0.142 \\
\hline
\end{tabular}

Notes: This table compares loan access, membership and savings across treatments. The sample is restricted to regular members (non-committee members). "Poor" is a dummy equal to 1 if an individual belongs to the bottom 25\% of the group wealth score distribution at Baseline. "Has no loan" is a dummy equal to 1 if an individual had no loans at Baseline. \#loans received is the number of loans received from the group (equals 0 if no loans were received in the past year). Amount borrowed (in UGX) is the total value of any loans taken in the past year (takes a value of 0 if no loans were received). Amount ever saved in the group (in UGX) is the amount saved since group formation. All regressions include branch fixed effects and robust standard errors clustered at the group level. Endline results also include sample weights to account for the fact that across relevant sub-groups, different proportions of the Baseline members were interviewed at Endline (see Table A.1 for more details). ${ }^{*} p<0.1,{ }^{* *} p<0.05,{ }^{* * *} p<0.01$. 


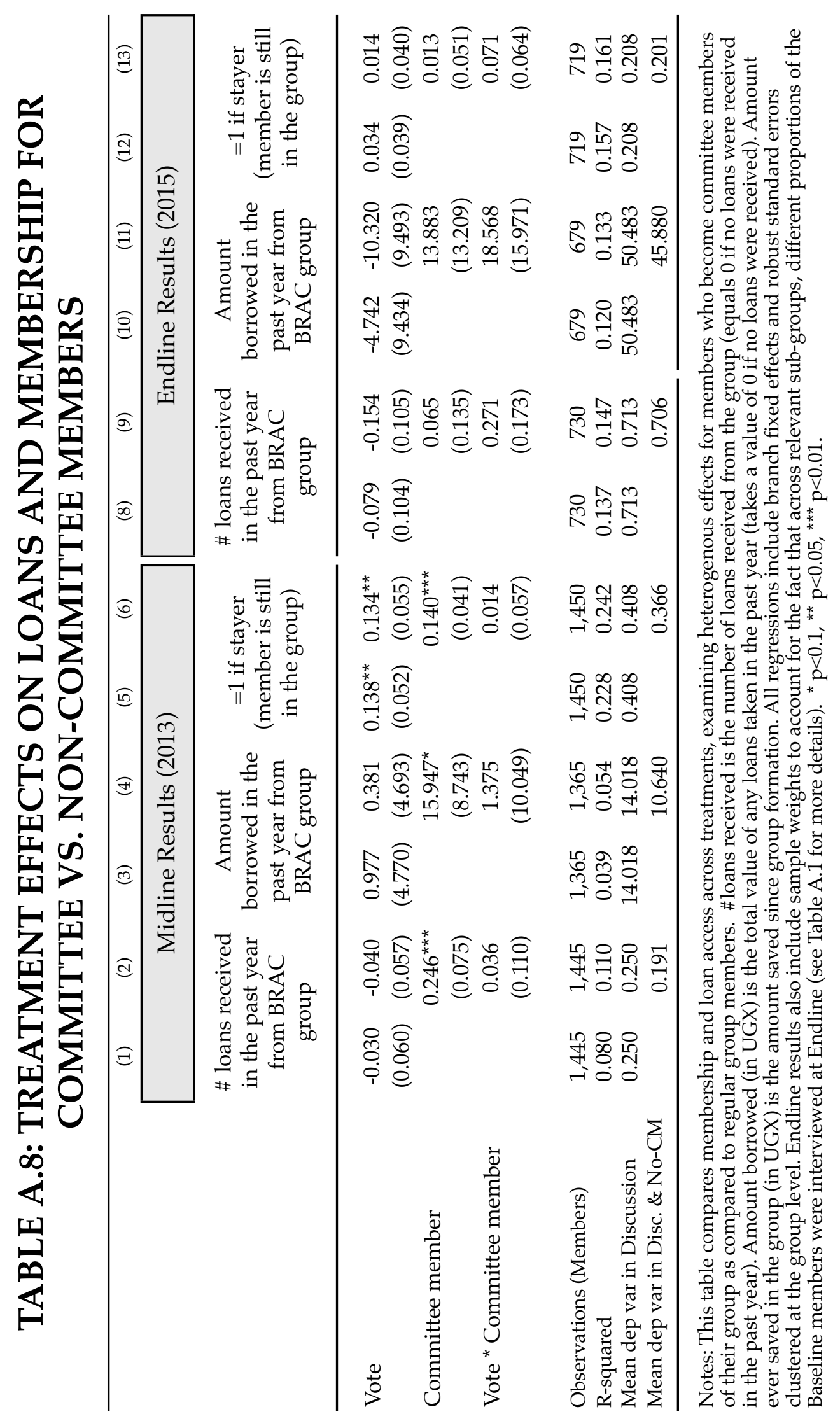




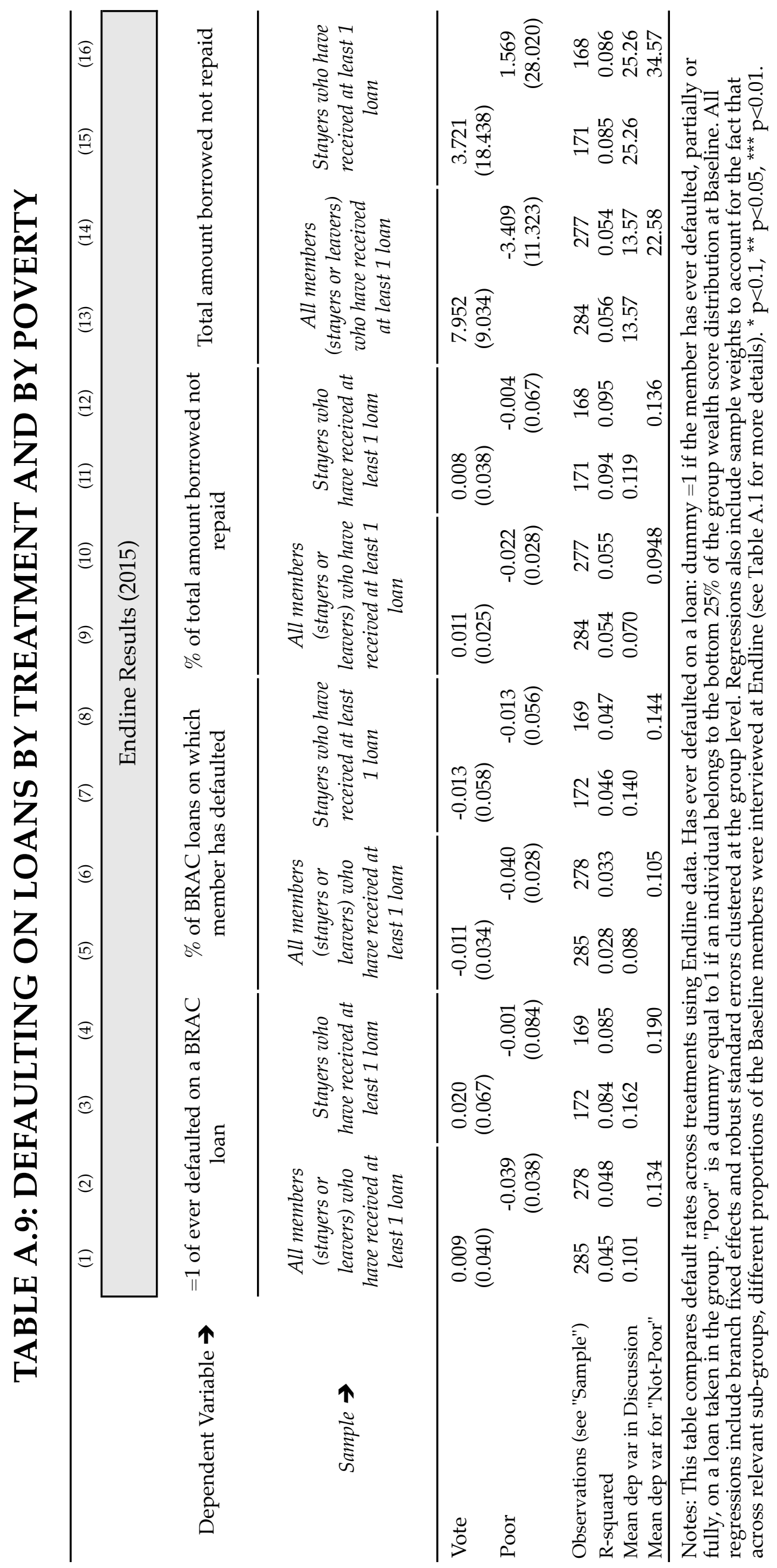




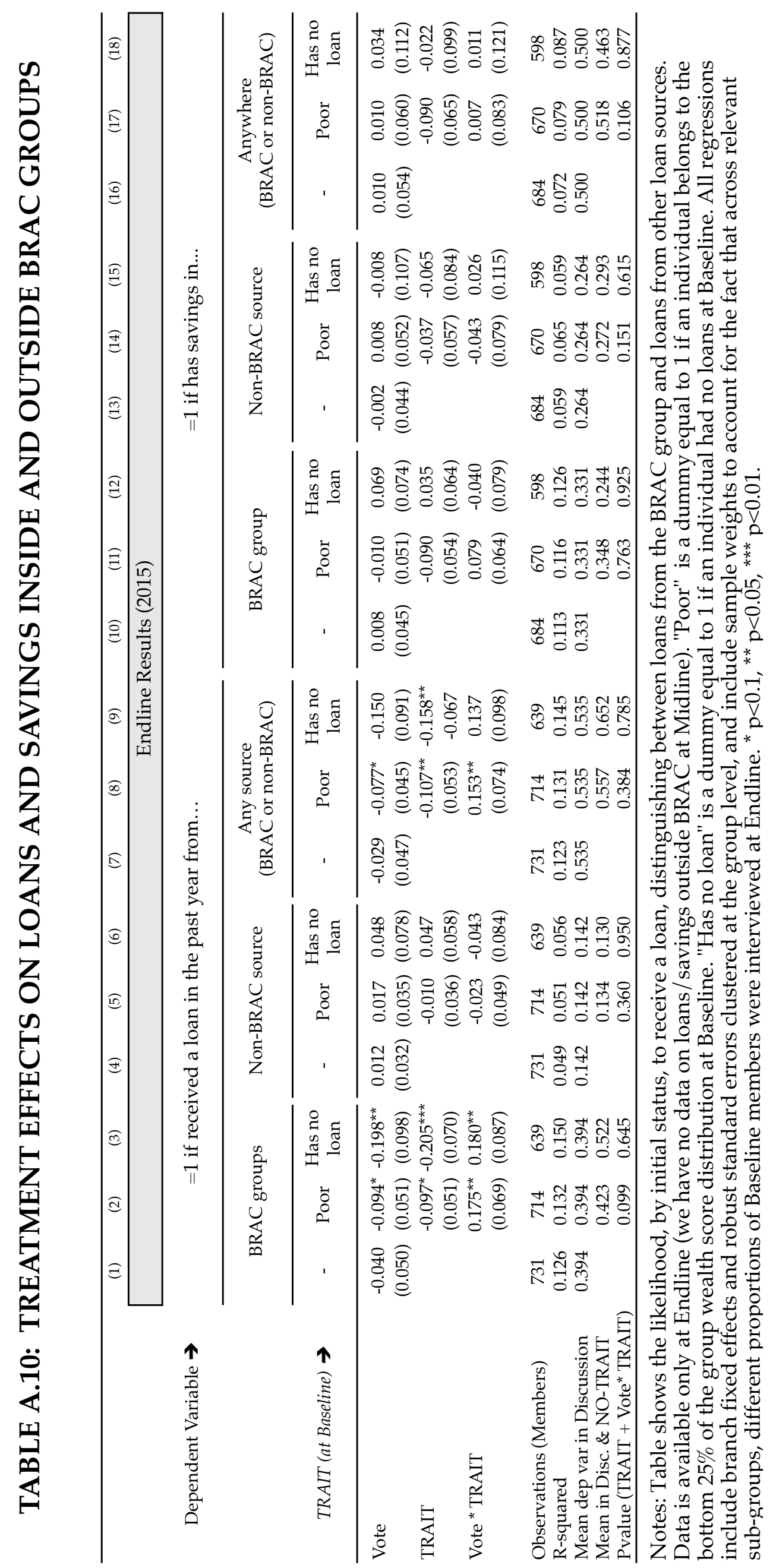




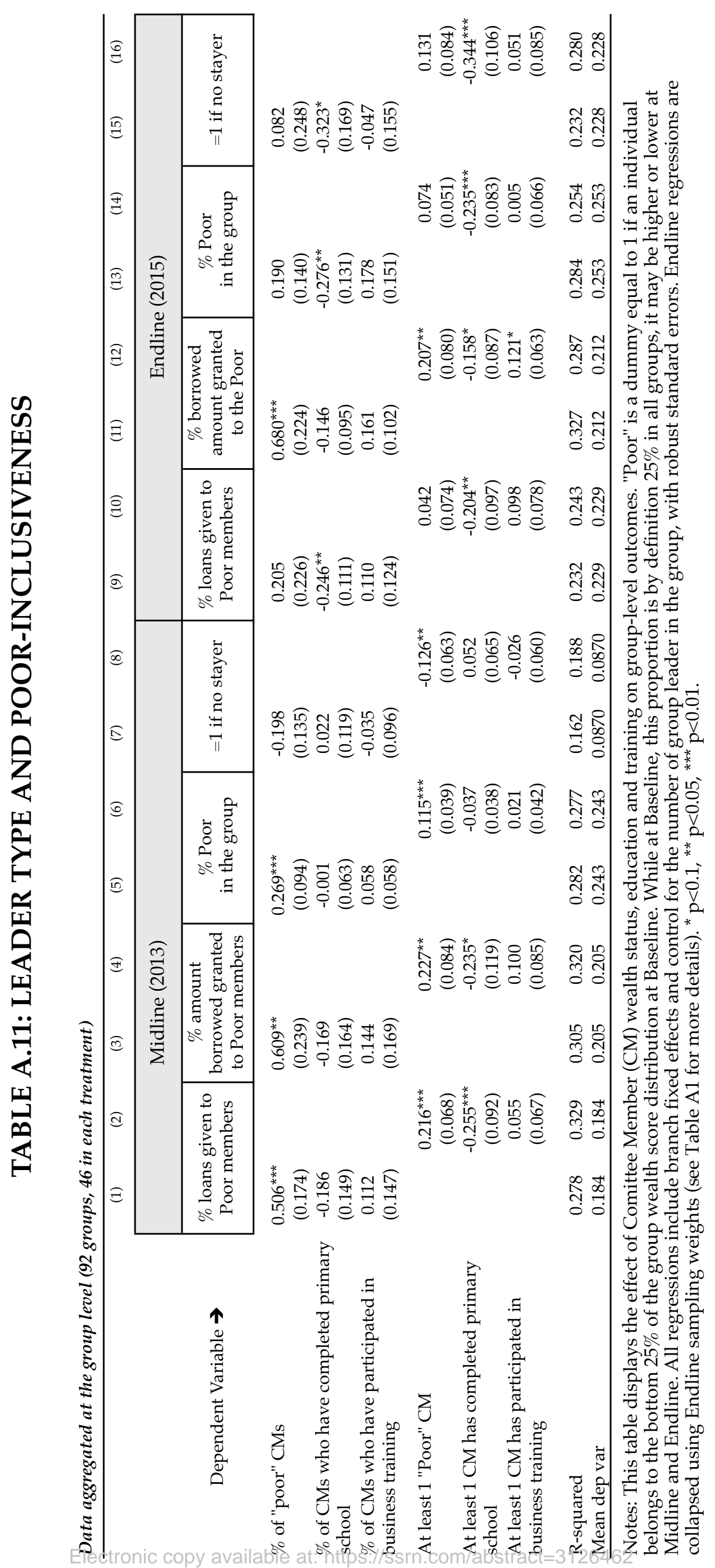




\section{TABLE A.12: PERCEIVED FAIRNESS OF THE SELECTION RULES}

\begin{tabular}{|c|c|c|c|c|c|c|c|}
\hline \multirow[b]{2}{*}{ SAMPLE $\rightarrow$} & $(1)$ & $(2)$ & $(3)$ & $(4)$ & $(5)$ & (6) & $(7)$ \\
\hline & \multicolumn{3}{|c|}{$\begin{array}{l}\text { Non-members of BRAC group when } \\
\text { election took place }\end{array}$} & \multicolumn{4}{|c|}{$\begin{array}{c}\text { Members of BRAC group when election took } \\
\text { place }\end{array}$} \\
\hline \multirow[t]{2}{*}{ Dependent Variable $\rightarrow$} & \multicolumn{3}{|c|}{$\begin{array}{l}=1 \text { if member finds Vote procedure } \\
\text { more "fair" than Discussion procedure }\end{array}$} & \multicolumn{2}{|c|}{$\begin{array}{c}=1 \text { if member finds Vote } \\
\text { procedure more "fair" } \\
\text { than Discussion } \\
\text { procedure }\end{array}$} & \multicolumn{2}{|c|}{$\begin{array}{l}=1 \text { if member feels } \\
\text { satisfied with the way } \\
\text { the CMs were chosen }\end{array}$} \\
\hline & \multicolumn{3}{|c|}{ Average $=43 \%$} & \multicolumn{2}{|c|}{ Average $=43 \%$} & \multicolumn{2}{|c|}{ Average $=88 \%$} \\
\hline Vote & $\begin{array}{c}0.016 \\
(0.036)\end{array}$ & & $\begin{array}{l}-0.029 \\
(0.078)\end{array}$ & $\begin{array}{c}0.033 \\
(0.040)\end{array}$ & $\begin{array}{l}0.024 \\
(0.047)\end{array}$ & $\begin{array}{l}-0.015 \\
(0.026)\end{array}$ & $\begin{array}{l}-0.029 \\
(0.027)\end{array}$ \\
\hline Poor (Bottom 25\% of wealth score) & & $\begin{array}{l}-0.054 \\
(0.047)\end{array}$ & $\begin{array}{l}-0.079 \\
(0.062)\end{array}$ & & $\begin{array}{c}0.006 \\
(0.076)\end{array}$ & & $\begin{array}{l}-0.058 \\
(0.052)\end{array}$ \\
\hline Vote ${ }^{*}$ Poor & & & $\begin{array}{c}0.051 \\
(0.096)\end{array}$ & & $\begin{array}{c}0.059 \\
(0.093)\end{array}$ & & $\begin{array}{c}0.045 \\
(0.067)\end{array}$ \\
\hline Observations & 397 & 397 & 397 & 703 & 688 & 703 & 688 \\
\hline R-squared & 0.050 & 0.069 & 0.070 & 0.061 & 0.064 & 0.048 & 0.053 \\
\hline Mean in Discussion & 0.434 & 0.434 & 0.434 & 0.404 & 0.404 & 0.900 & 0.900 \\
\hline Coefficient (Poor + Vote $^{*}$ Poor $)$ & & & -0.028 & & 0.065 & & -0.013 \\
\hline P-value (Poor + Vote* Poor) & & & 0.699 & & 0.224 & & 0.745 \\
\hline
\end{tabular}

Notes: At the time of Endline, we asked a random sample of BRAC local center (club) members, that were not part of the savings group when the election took place, which one of the two treatments they perceive as more fair (Columns 1-3). At Endline, the BRAC saving group's members who were part of the savings group when the election took place were asked the same general question about the two procedures (Columns 4-5) and were also asked about their satisfaction with the way the selection happened in their own group (Columns 6-7). "Poor" is a dummy equal to 1 if an individual belongs to the bottom $25 \%$ of the group wealth score distribution at Baseline. All regressions include branch fixed effects and robust standard errors clustered at the group level. All regressions also include sample weights to account for the fact that across relevant sub-groups, different proportions of the Baseline members were interviewed at Endline (see Table A.1 for more details). ${ }^{*} \mathrm{p}<0.1,{ }^{* *} \mathrm{p}<0.05,{ }^{* * *} \mathrm{p}<0.01$. 